\title{
Diagnostic criteria for Idiopathic Pulmonary Fibrosis: a Fleischner Society White Paper
}

David A Lynch, MB

Nicola Sverzellati, MD

William D Travis, MD

Kevin K Brown, MD

Thomas V Colby, MD

Jeffrey R Galvin, MD

Jonathan G Goldin, MD

David M Hansell, MD

Yoshikazu Inoue, MD

Takeshi Johkoh, MD

Andrew G Nicholson, DM

Shandra Knight, MS

Suhail Raoof, MD

Luca Richeldi, MD

Christopher J Ryerson, MD

Jay H Ryu, MD

Athol U Wells, MD

\section{Corresponding Author:}

\section{David A Lynch, MB}

Department of Radiology

National Jewish Health

1400 Jackson Street

Denver, CO 80206

Phone: 303-270-2810

E-mail: LynchD@NJHealth.org

Fax: 303-270-2073 


\section{Author details}

\begin{tabular}{|c|c|c|}
\hline Name & Institution & Address \\
\hline David A Lynch, MB* & National Jewish Health & 1400 Jackson St. Denver, CO 80206, USA \\
\hline Nicola Sverzellati, MD & University of Parma & V. Gramsci 14, PR 43126 Parma, Italy \\
\hline William D Travis, MD* & $\begin{array}{l}\text { Memorial Sloan Kettering } \\
\text { Cancer Center }\end{array}$ & $\begin{array}{l}1275 \text { York Ave., New York, NY 10065, } \\
\text { USA }\end{array}$ \\
\hline Kevin K Brown, MD* & National Jewish Health & 1400 Jackson St. Denver, CO 80206, USA \\
\hline Thomas V Colby, MD* & Mayo Clinic Scottsdale & $\begin{array}{l}13400 \text { E. Shea Blvd., Scottsdale, AZ } \\
85259 \text {, USA }\end{array}$ \\
\hline Jeffrey R Galvin, MD* & University of Maryland & $\begin{array}{l}22 \text { S. Greene St., Baltimore, MD 21201, } \\
\text { USA }\end{array}$ \\
\hline $\begin{array}{l}\text { Jonathan G Goldin, } \\
\text { MD* }\end{array}$ & $\begin{array}{l}\text { David Geffen School of Medicine } \\
\text { at UCLA }\end{array}$ & $\begin{array}{l}1250 \text { 16th St. - \#2340, Santa Monica, CA } \\
\text { 90404, USA }\end{array}$ \\
\hline David M Hansell, MD* & $\begin{array}{l}\text { Royal Brompton and Hospital } \\
\text { NHS Foundation Trust and } \\
\text { National Heart and Lung } \\
\text { Institute, Imperial College }\end{array}$ & $\begin{array}{l}\text { Sydney St., London SW3 6NP, United } \\
\text { Kingdom }\end{array}$ \\
\hline Yoshikazu Inoue, MD* & $\begin{array}{l}\text { National Hospital Organization } \\
\text { Kinki-Chuo Chest Medical Center }\end{array}$ & $\begin{array}{l}1180 \text { Nagasone-cho, Kita-ku, Sakai, } \\
\text { Osaka, 591-8555 Japan }\end{array}$ \\
\hline Takeshi Johkoh, MD* & $\begin{array}{l}\text { Kinki Central Hospital of Mutual } \\
\text { Aid Association of Public School } \\
\text { Teachers }\end{array}$ & $\begin{array}{l}\text { 3-1 Kurumazuka, 664-8533 Itami - } \\
\text { Hyogo, Japan }\end{array}$ \\
\hline $\begin{array}{l}\text { Andrew G Nicholson, } \\
\text { DM* }^{*}\end{array}$ & $\begin{array}{l}\text { Royal Brompton and Hospital } \\
\text { NHS Foundation Trust and } \\
\text { National Heart and Lung } \\
\text { Institute, Imperial College }\end{array}$ & $\begin{array}{l}\text { Sydney St., London SW3 6NP, United } \\
\text { Kingdom }\end{array}$ \\
\hline Shandra Knight, MS & National Jewish Health & 1400 Jackson St. Denver, CO 80206, USA \\
\hline Suhail Raoof, MD* & Lenox Hill Hospital & $\begin{array}{l}100 \text { East 77th Street, New York, NY } \\
\text { 10075, USA }\end{array}$ \\
\hline Luca Richeldi, MD* & $\begin{array}{l}\text { Agostino Gemelli University } \\
\text { Hospital of the Catholic } \\
\text { University of the Sacred Heart }\end{array}$ & Rome, ItalyJ \\
\hline $\begin{array}{l}\text { Christopher J Ryerson, } \\
\text { MD }\end{array}$ & $\begin{array}{l}\text { University of British Columbia } \\
\text { and St. Paul's Hospital }\end{array}$ & $\begin{array}{l}1081 \text { Burrard St. Vancouver, BC, Canada } \\
\text { V6Z1Y6 }\end{array}$ \\
\hline Jay H Ryu, MD* & Mayo Clinic Rochester & $\begin{array}{l}200 \text { First St. SW, Gonda } 18 \\
\text { South, Rochester, MN 55905, USA }\end{array}$ \\
\hline Athol U Wells, MD* & $\begin{array}{l}\text { Royal Brompton and Hospital } \\
\text { NHS Foundation Trust and } \\
\text { National Heart and Lung } \\
\text { Institute, Imperial College }\end{array}$ & $\begin{array}{l}\text { Sydney St., London SW3 6NP, United } \\
\text { Kingdom }\end{array}$ \\
\hline
\end{tabular}




\section{Author contributions}

DAL and SK developed and implemented systematic search strategy. CJR advised on systematic search. All authors participated in literature search. DAL, NS, WDT, KKB, and AUW created the first draft of the paper. All authors critically reviewed the manuscript. All authors approved the final version to be published and take accountability for the work.

\section{Conflicts of interest}

DMH reports personal fees from AstraZeneca, personal fees from Sanofi, personal fees from Boehringer Ingelheim, personal fees from Roche, outside the submitted work. YI reports personal fees from Boehringer Ingelheim, Asahi Kasei, grants from Japanese Ministry of Health Labour, and Welfare, grants from Aapan Agency for Medical Research and Development, outside the submitted work. DAL reports grants from NHLBI, personal fees from Parexel, other from Veracyte, personal fees from Boehringer Ingelheim, personal fees from Genentech/Roche, outside the submitted work. AGN reports personal fees from Boehringer Ingelheim, personal fees from Sanofi, personal fees from Med Quantitative Image Analysis, personal fees from Roche, outside the submitted work. LR reports grants and personal fees from Boehringer Ingelheim; grants and personal fees from InterMune, personal fees from Medimmune, personal fees from Biogen-Idec, personal fees from Sanofi-Aventis, personal fees from Roche, personal fees from Takeda, personal fees from ImmuneWorks, personal fees from Shionogi, outside the submitted work. CJR reports grants and personal fees from Boehringer Ingelheim, grants and personal fees from Hoffmann La Roche, outside the submitted work. NS reports personal fees from Roche, personal fees from Boehringer Ingelheim, outside the submitted work. AUW reports personal fees from Intermune/Roche, personal fees from Boehringer Ingelheim, personal fees from Bayer, personal fees from Gilead, outside the submitted work. KKB, TVC, JRG, JGG, TJ, SK, SR, JHR, and WDT declare no significant conflicts of interest associated with this manuscript. 


\section{Summary}

This White Paper provides an updated approach to the diagnosis of Idiopathic Pulmonary Fibrosis (IPF), based on a systematic review of the literature, and the expert opinion of members of the Fleischner Society. A checklist is provided for clinical evaluation of patients with suspected usual interstitial pneumonia (UIP). The role of computed tomography (CT) is expanded to permit diagnosis of IPF without surgical lung biopsy in select cases in the context of a probable UIP pattern. . Additional investigations, including surgical lung biopsy, should be considered in patients with either clinical or CT findings that are indeterminate for IPF. Multidisciplinary diagnosis is particularly important in the decision to perform additional diagnostic evaluation, in integrating biopsy results with clinical and CT features, and in establishing a working diagnosis of IPF if lung tissue is not available. A working diagnosis of IPF should be reviewed at regular intervals as it may change. Criteria are presented to establish confident and working diagnoses of IPF.

\section{Take home messages}

A confident diagnosis of IPF may be made in the correct clinical context when the CT shows a pattern of definite or probable UIP.

If the clinical context is indeterminate for IPF, or the CT pattern is not definite or probable UIP, biopsy should be considered to confirm the presence of a UIP histologic pattern, and a confident diagnosis of IPF may be made based on multidisciplinary evaluation.

If diagnostic tissue is not available, a working diagnosis of IPF may be made after careful multidisciplinary evaluation.

All patients with an IPF diagnosis should have this diagnosis reviewed at regular intervals. 


\section{Introduction}

The approval of medical therapies for idiopathic pulmonary fibrosis (IPF), marks a new era in our approach to this deadly disease; offering hope to patients and their physicians, a clearer path forward for companies interested in the development of new treatments, and the potential for new biologic insights. It also offers us the opportunity to review our approach to diagnosis. The diagnostic criteria for IPF published in 2011(1) have been critical for defining entry criteria and ensuring appropriate recruitment for recent prospective clinical trials.(2-7) In turn, these trials, with large cohorts of wellcharacterized patients, have provided us with considerable new clinically relevant information about disease presentation and its longitudinal behavior. $(8,9)$ The specific inclusion and exclusion criteria used in these studies have also highlighted the limitations of our current diagnostic guidelines, and indicated opportunities for improvement. $(9,10)$

Our current approach to the diagnosis requires the collaboration of multiple specialists, the ability to interpret and communicate complex clinical data patterns, and to synthesize uncertain or sometimes conflicting information. The clinician interprets the history and physical exam to develop a clinical context, the thoracic radiologist interprets the pattern present on high resolution computerized tomographic (CT) scanning of the chest and, if needed, the pathologist interprets the histopathologic pattern seen on lung biopsy. All of this information must be shared using a common language, in order for clinical decision-making to occur. Since "classic" clinical stories and patterns are uncommon, some degree of clinical uncertainty is often present; acknowledgement of this limitation and a clear plan to address it are essential. 
For this Fleischner Society White Paper, we identified specific questions pertaining to the diagnosis of IPF and conducted a systematic review to identify evidence related to these topics that had been published since the 2011 guidelines. Based on this review of the literature, combined with expert opinion, we provide IPF diagnostic criteria that we believe will have greater utility for clinicians, clinical trialists, trial sponsors, and other interested groups.

\section{Methodology}

The international multidisciplinary panel included 18 Fleischner Society members with expertise in interstitial lung disease (ILD) and evidence based medicine (9 pulmonologists, 6 radiologists, and 3 pathologists), as well as a medical librarian expert (SK). Several face to face meetings were held, in addition to monthly conference calls.

\section{Search strategy and selection criteria}

The panel developed key questions believed to be important for the diagnosis of IPF (Table 1). A literature search was performed in on the Ovid platform in MEDLINE, Embase, Cochrane Central Register of Controlled Trials, Database of Abstracts and Reviews of Effects, and Cochrane Database of Systematic Reviews, to identify new publications relevant to these key questions, assisted by a medical librarian experienced with literature searches for pulmonary diseases. Because the 2011 ATS-ERS statement(1) was based on a systematic literature search that ended in May 2010, the systematic search for this document searched for publications from June 2010 through April 2016. An updated search was run through April 2017. Details of the search strategy are provided in Appendix 1. 
The committee was divided into subgroups assigned to specific sections and questions. Reviewers from each subgroup used a two-step screening process based on article title and abstract, with predefined inclusion and exclusion criteria, to identify articles for inclusion in the literature review. Articles were selected for inclusion if they were original scientific papers that dealt with one of the key questions, had a study population $>10$ subjects, and had an English language abstract available. The subgroups reviewed the relevant literature and produced the first draft of their respective sections. The sections were compiled by the committee chair and a complete first draft was created. This document was reviewed and edited by all committee members. The document was then circulated for comment to all members of the Fleischner Society and appropriate revisions were made. The final document was approved by all authors.

\section{Clinical}

\section{What specific clinical information is required to exclude other forms of interstitial lung}

\section{disease?}

A diagnosis of IPF requires exclusion of alternative causes of fibrosing ILD, broadly grouped into systemic and exposure-related disorders. The clinical evaluation requires an inquiring mind, a clear understanding of the differential diagnosis, and a comprehensive structured approach to help exclude known causes and associations. A clear focus of the clinical examination should be to establish the clinical probability of IPF, particularly increased age (>60), male sex, and history of cigarette smoking. (11) Table 2 lists some additional important clinical questions to address in the history of an individual with suspected IPF, and the specific clinical challenges of systemic autoimmune disease, chronic hypersensitivity pneumonitis (HP), and familial pulmonary fibrosis are briefly discussed below. 
Systematic evaluation for CTD is necessary in subjects presenting with suspected IPF, and identification of a defined CTD (e.g. rheumatoid arthritis) excludes IPF. Some patients with fibrosing lung disease have serologic abnormalities and/or symptoms suggestive of an autoimmune disease, but do not meet criteria for a specific CTD (i.e. interstitial pneumonia with autoimmune features (IPAF)). (3, 12-17) A substantial proportion of patients with IPAF have imaging and/or pathologic features of UIP,(18) with similar survival to IPF. The proposed criteria for IPAF have not at this point been sufficiently validated to justify exclusion from the diagnosis of IPF, and these individuals should be considered to have IPF if they meet the diagnostic criteria outlined in this paper.

In every patient with fibrosing ILD, it is important to identify exposure to antigens that may result in HP, and long lists of such antigens are available.(19) However, the clinical significance of such exposures can be difficult to determine, and there are no universally accepted criteria for chronic HP. In general, antigen exposure is more likely to be clinically significant if the exposure coincides with or precedes the onset of symptoms, if symptoms fluctuate temporally in relation to the exposure, and if there are other imaging, histologic, or laboratory features suggestive of chronic HP (20). The clinical significance of histologic findings suggesting HP without known exposure (which accounts for as many as $50-60 \%$ of cases of histologic chronic fibrotic HP $(21,22))$ remains unclear; it is likely that some of these cases are due to currently unrecognized antigens. The clinical utility of serum precipitins in the diagnosis of HP remains uncertain (23). However, demonstration of lymphocytosis on cellular analysis of bronchoalveolar lavage fluid can be helpful in supporting the diagnosis of HP (23-26) Some patients with a UIP pattern of pulmonary fibrosis have occupational or medication exposures and these patients should be discussed at multidisciplinary conference to review the relevance of these exposures (27-33). 
Pulmonary fibrosis, including IPF, may cluster in families. Familial forms of IPF may be related to common genetic variants (for example the rs35705950 promoter variant associated with increased MUC5B expression), or may be related to rare variants, some in genes associated with telomere maintenance or surfactant metabolism (34). The radiologic presentation of familial IPF may differ from that of sporadic IPF, with a higher prevalence of diffuse or upper lung involvement (35), and the pathology may also be different than non-familial IPF, with a higher prevalence of unclassifiable fibrosis on surgical lung biopsy (36). While some of these patients will not meet a strict definition of IPF because they fail to meet histologic or imaging criteria, careful multidisciplinary consideration may result in a working diagnosis of IPF in selected cases.

\section{Imaging}

CT plays a central role in the evaluation of all patients with ILD, and can be diagnostic in many situations. When IPF is in the differential, the radiologist must indicate whether a usual interstitial pneumonia (UIP) pattern is present and, if so, what is the interpreter's level of confidence. Because of its importance, a systematic approach to CT of the chest in suspected UIP is needed. This entails evaluation of image quality, precise assessment of specific disease features using standard terminology, and the determination of distribution and extent. This approach should permit the radiologist to classify the CT pattern into one of four categories (Table 3).

High quality CT images are essential. Optimal quality CT requires the use of thin section $(<2 \mathrm{~mm})$ and high spatial resolution reconstruction (37). Images should be obtained at full inspiration to total lung capacity. Inadequate inspiration increases lung attenuation, potentially leading to misinterpretation of key findings (e.g. ground glass opacity and fine reticulation) (38). Volumetric CT acquisition is preferred 
to non-contiguous imaging as it improves characterization of patchy disease and delineation of disease extent, clarifies disease distribution, allows identification of ancillary findings, facilitates differentiation between honeycombing and traction bronchiectasis, and optimizes comparison with follow-up images to assess progression or improvement $(39,40)$. Acceptable CT scans may be obtained with a reduced dose technique using tools such as automatic tube current modulation, optimization of tube potential, beam-shaping filters and dynamic z-axis collimators (41). Reduced-dose CT scans reconstructed with iterative algorithms may allow the detection of subtle interstitial abnormalities, comparable to standard dose CT images (42). Prone CT imaging is useful when disease is suspected in patients with normal or minimally abnormal chest radiographs, and particularly when there is dependent opacification, mimicking disease, on supine CT images (43). Prone CT may also facilitate the diagnosis of honeycombing, reducing observer variation in diagnosis of IPF (44). Expiratory imaging is useful to identify air trapping, a feature that may suggest an alternative diagnosis such as chronic HP or CTD (45). Prone and expiratory acquisitions may be performed with non-contiguous imaging and at lower dose than the inspiratory CT (46).

\section{What are the critical CT features that can be used to make the diagnosis of UIP?}

\section{Honeycombing}

Identification of honeycombing on chest CT is important for both diagnosis and prognosis in fibrotic ILD $(1,47-50)$. Honeycombing is a key characteristic of the UIP pattern, and is typically located in the dorsal, basal, subpleural regions of the lung, but may be seen only in the upper lungs in otherwise typical cases. On $\mathrm{CT}$, honeycombing is defined as clustered, thick-walled, cystic spaces of similar diameters, generally measuring between 3-5 mm, but occasionally up to $25 \mathrm{~mm}$ in size (Figure 1) (51). While honeycombing 
may consist of several stacked layers of cysts, a single subpleural layer of 2-3 contiguous cysts is adequate for diagnosis (Figure 1f) (52). Honeycomb cysts visually identified on CT are usually thought to correspond to cysts on gross pathological specimens (40), but they may also correlate with foci of traction bronchiolectasis (53). The much smaller cysts seen in histopathologic specimens and termed 'microscopic honeycombing', are beyond the spatial resolution of CT and often do not correlate with honeycombing on CT (54). Micro-CT has shown that honeycombing develops at the periphery of the pulmonary lobule in and around collapsed alveoli and connecting bronchioles (55).

There is significant interobserver variation in the identification of honeycombing on CT, most frequently because of the coexistence of other abnormalities such as emphysema and traction bronchiectasis. In a recent large study where observers were presented with single CT images, there was disagreement about the presence or absence of honeycombing in approximately one third of cases, particularly when this feature was mixed with traction bronchiectasis, large cysts, and superimposed paraseptal or centrilobular emphysema (56). Review of sequential multiplanar images is particularly important in such cases.

\section{Reticular pattern}

The reticular pattern is characterized by a network of fine lines. In UIP, reticulation is irregularly spaced with a mixture of thick and thin lines, in contrast to NSIP where spacing is more regular, and lines are more homogeneous in thickness.

\section{Traction bronchiectasis}

Traction bronchiectasis and bronchiolectasis is a hallmark of lung fibrosis on chest imaging, an important prognostic marker in UIP (Figure 1) (57). This feature represents irregular bronchial and bronchiolar 
dilatation caused by retractile fibrosis in the surrounding lung parenchyma (51). In UIP, traction bronchiectasis is predominantly seen in the periphery of the lungs, and affected airways typically demonstrate an irregular varicose appearance. This appearance, along with the background of lung fibrosis represented by reticulation and ground glass opacity, helps to distinguish traction bronchiectasis from 'freestanding' bronchiectasis that is unrelated to fibrosis (52). Traction bronchiectasis is also a salient feature of fibrotic NSIP, but the dilated bronchi in this condition are usually more central (58). Distinguishing honeycombing from traction bronchiectasis may be challenging though diagnostically important, since honeycombing increases the likelihood of UIP. Conglomerated peripheral traction bronchiectasis or bronchiolectasis may resemble honeycombing, particularly when it predominates at the lung bases. Viewing of sequential multiplanar CT images as well as post-processing reconstruction algorithms (e.g. minimum intensity projection) may help differentiate honeycombing from traction bronchiectasis; however, they often coexist (40). Indeed, recent work suggests that at least some honeycomb cysts may contain bronchiolar markers and may therefore sometimes represent "end-stage" traction bronchiolectasis (59).

Overall, the identification of traction bronchiectasis appears to be associated with slightly less interobserver variation than honeycombing, with moderate to good agreement reported for its presence or absence on $\mathrm{CT}(49,57,60)$.

\section{Ground glass opacity}

Pure ground glass opacity is not usually a feature of UIP. However, many patients with fibrotic lung disease have ground glass opacity admixed with reticular abnormality and/or traction bronchiectasis (Figure 1f). In this context, the ground glass opacity should be regarded as part of the fibrotic 
process;(61) however, UIP is unlikely when pure ground glass opacity is present as an isolated finding of diffuse ILD. The presence of abundant ground glass opacity in a patient with fibrotic ILD, particularly in non-fibrotic areas of lung, should suggest acute exacerbation. $(62,63)$

\section{Other findings}

Mild mediastinal lymph node enlargement is evident on CT in approximately $70 \%$ of cases of UIP (64). Occasionally, fine linear or small nodular foci of calcification are observed within areas of fibrosis as a result of ossification (65), and these are seen more frequently in UIP (29\%) than in other diffuse fibrosing lung diseases (8\%) (66). Some patients with otherwise typical UIP may also have some features of idiopathic pleuropulmonary fibroelastosis, with bilateral irregular pleuroparenchymal thickening in the upper and mid lungs (67). Until the entity of overlapping UIP and pleuropulmonary fibroelastosis can be further clarified, patients otherwise meeting criteria for UIP/IPF should be considered to have IPF, whether or not an element of PPFE is present.

\section{How can UIP be distinguished on CT from other fibrosing interstitial pneumonias?}

A diagnosis of IPF cannot be established from CT appearances alone. The UIP pattern seen in IPF is often radiologically indistinguishable from the UIP pattern seen in some cases of CTD, chronic HP, and pneumoconiosis, and others $(28,29,33,68)$. Also, sarcoidosis may very rarely present with CT features resembling a typical UIP pattern (69).

The identification of a UIP pattern may be more challenging in smokers who have both lung fibrosis and emphysema, a combination observed in about one third of IPF cases $(70,71)$. In a study of 40 patients 
with lung fibrosis and concurrent emphysema, chest imaging was able to predict the underlying pattern seen on surgical lung biopsy in 30 (44\%) of 68 readings, including 20 (50\%) for UIP and 10 (36\%) for NSIP.(72) Radiologists should describe the extent and relative severity of coexisting emphysema in patients with the UIP pattern as this also influences patient management and prognosis.(73) Smokers may exhibit the pathologic entity "airspace enlargement with fibrosis (AEF)", which may resemble honeycomb cysts on CT. $(74,75)$ However, AEF tends to predominate in the upper to mid lung zones, spares the most peripheral parts of the lung and displays thinner "walls" than the cysts of honeycombing (76). AEF tends not to be associated with other CT signs of lung fibrosis, with the exception of combined pulmonary fibrosis and emphysema, which is characterized by the presence of emphysema, cysts and a UIP pattern of fibrosis (77).

It is important to differentiate the CT pattern of chronic HP and CTD from UIP when possible. Features of HP include an upper or mid-lung distribution (though about $1 / 3$ of cases have lower lung predominance),(78) profuse poorly defined centrilobular nodules, and mosaic attenuation or air trapping. Mosaic attenuation and air trapping are helpful in distinguishing HP from UIP,(78) particularly when present in relatively spared/non-fibrotic lung, but are frequently present within areas of advanced fibrosis in the lower lobes of patients with IPF. The confident identification of air-trapping diminishes as the features of lung fibrosis becomes more extensive and coarser (and more in keeping with the typical UIP pattern).(79) In a recent study, mosaic attenuation or air trapping was the source of CT-pathologic discordance in $72 \%$ of cases with a final diagnosis of IPF.(10) Patients with CTDs, particularly rheumatoid arthritis, can also develop UIP. The presence of pleural effusion, esophageal dilation, or pericardial abnormality in a patient with a UIP pattern should raise the possibility of an underlying CTD.(80) 
In several studies, up to $60 \%$ of cases that underwent biopsy and showed typical histologic UIP did not show a typical CT chest imaging pattern $(10,49,81)$. Thus, in the correct clinical setting, a diagnosis of IPF is not excluded by CT appearances more suggestive of other interstitial lung diseases such as NSIP, CHP, or sarcoidosis (81). The UIP pattern most frequently overlaps with fibrotic NSIP. In a study of 92 patients with an idiopathic interstitial pneumonia proven by surgical lung biopsy (including 20 with UIP, 16 with cellular NSIP and 16 with fibrosing NSIP), observers made the correct chest imaging pattern diagnosis in $79 \%$ of the cases (82). Multivariate logistic regression analysis showed that a UIP pattern was independently predicted by the extent of honeycombing. Also, subpleural sparing is a CT feature in up to $60 \%$ of cases of NSIP, and is not usually observed in UIP (78).

\section{Diagnostic Categories of CT pattern (Table 3)}

The 2011 guideline on IPF published by ATS/ERS/JRS/ALAT defines three diagnostic categories based on CT appearance: UIP, possible UIP and inconsistent with UIP (1). This classification allowed some standardization of diagnostic certainty and was shown to have some prognostic value in two studies (83, 84); however, a larger series showed no difference in survival after adjustment for extent of fibrosis (85). . In a large study, inter-observer agreement across these diagnostic categories was moderate for both fellows and thoracic radiologists (86).A review of the current CT classification of UIP is necessary in light of these findings.

In the appropriate clinical context, a typical UIP pattern on CT is sufficient to secure a diagnosis of UIP/IPF without the need to perform surgical lung biopsy or other invasive testing $(87,88)$. The typical UIP pattern is characterized by reticular opacities with obligatory honeycombing, usually associated with traction bronchiectasis (Figure 1). Ground glass opacity, if present, is usually admixed with reticular 
abnormality and honeycombing (89). Such abnormalities are characteristically basal and peripheral, though often patchy (90). Some degree of upper lung involvement (including honeycombing) is usual $(87,90)$, and sometimes the craniocaudal distribution may be relatively uniform in patients with otherwise typical UIP. The distribution may be asymmetric in up to $25 \%$ of cases (91). The specificity of a confident diagnosis of the typical UIP pattern on CT has been reported to be $94-100 \%$ in most studies $(78,88,92)$. The lower sensitivity $(43 \%-78 \%)$ is accounted for by either the lack of honeycombing or the presence of atypical findings, which impair the ability to diagnose UIP based on CT alone $(78,88,92)$. In a recent IPF clinical trial, typical UIP was found on CT in only $53 \%$ of enrolled patients, and no difference in disease behavior or treatment responsiveness was identified between patients with and without typical UIP (9).

The 2011 ATS/ERS/JRS/ALAT clinical practice guideline stated that a biopsy is necessary to confirm the underlying histopathologic pattern diagnosis of UIP in patients with possible UIP, which was defined as the presence of reticular abnormality and traction bronchiectasis with a subpleural and lower zone predominance and without honeycombing. However, recent studies have shown that the absence of honeycombing should not exclude a diagnosis of UIP if all other features of UIP are present (particularly subpleural and basal predominance and traction bronchiectasis). These CT findings can be regarded as representing a probable UIP pattern (Figure 2), with $82-94 \%$ of these patients having a probable or definite UIP histopathologic pattern on surgical lung biopsy $(8,54)$. The likelihood of UIP histology is greater in patients with high clinical probability of IPF (e.g., age greater than 60 , history of cigarette smoking, no history of other potential causes of fibrosis).(11, 93) 
A UIP pattern may still be found on histology in patients who lack a typical or probable UIP pattern

(Figure 3). (54). These cases, which might have been termed "inconsistent with UIP" under the 2011 guidelines, should be considered as indeterminate for UIP. In particular, areas of decreased attenuation or mosaic attenuation (e.g. bilateral or in more than three pulmonary lobes) have been observed in 21$35 \%$ of IPF cases (Figure 4) (78), and cannot be used to exclude IPF. The presence of mosaic attenuation and/or sharply defined lobular expiratory air trapping should always prompt clinical concern and multidisciplinary evaluation for underlying HP, particularly when it is extensive and present in nonfibrotic lung.

Many patients with fibrotic ILD have imaging features that clearly suggest a pattern other than UIP. Specifically, a clear upper lobe-predominance, subpleural sparing, consolidation, predominant ground glass opacity (in a clinically stable setting), diffuse nodules, and cysts are only very rarely observed in UIP. $(49,78,81)$

Further examples of the CT features of UIP, with complete scrollable image datasets and corresponding histology, may be found at http://get.pacsbin.com/fleischner/

\section{Pathology}

\section{When is surgical or other biopsy indicated in the diagnosis of IPF?}

The presence of a typical or probable UIP pattern on CT provides a diagnosis of IPF in the appropriate clinical context; no additional information is necessary, as discussed above. A surgical lung biopsy should be considered when the CT pattern is indeterminate or inconsistent with UIP, or when there are clinical features to suggest an alternative diagnosis (e.g. exposures suggestive of HP). 
The current IPF guidelines do not adequately address the diagnostic fate of patients who do not have a typical UIP pattern on CT and cannot, or choose not to, undergo a surgical lung biopsy. In this specific situation, bronchoscopy with transbronchial biopsy and BAL may provide information to increase or decrease the likelihood of an IPF diagnosis $(94,95)$. However, tissue obtained by transbronchial biopsy is usually inadequate for confident diagnosis of UIP (96). Identification of UIP on histology requires the specific low-power microscopic findings that can generally only be fully appreciated on a surgical lung biopsy. Individual features of a UIP pattern such as fibroblast foci that can occasionally be obtained via transbronchial biopsy are not specific for UIP. Although UIP features have been found in up to one third of transbronchial biopsies in IPF (97), there are no prospective studies utilizing an acceptable gold standard to show that transbronchial biopsy can be confidently used to diagnose IPF.

Despite advances in CT diagnosis, surgical lung biopsy remains an important modality for diagnosis of IPF in a large subset of patients who cannot be diagnosed based on clinical and imaging features alone (10, 81). Surgical lung biopsy is usually recommended for individuals with undiagnosed fibrosing ILD unless there are mitigating circumstances. Ideally, the biopsies should be taken from multiple lobes $(98,99)$, and should target areas of diseased but not end-stage lung. Each biopsy should measure at least $2-3 \mathrm{~cm}$ along the pleural axis and 1-2cm deep. (100) Biopsies measuring $4 \mathrm{~cm}$ in greatest dimension are achievable. (101)

Morbidity and mortality are a concern with surgical lung biopsy. In a review of 2820 surgical lung biopsies undertaken for suspected ILD from 1997-2008 in the United Kingdom, 30-day and 90-day mortalities were $2.4 \%$ and $3.9 \%$ respectively.(102) In a different US-based study of surgical lung biopsies 
performed between 2000 and 2011, in-hospital mortality was 1.7\% for elective procedures but significantly higher (16\%) for nonelective procedures.(103) Male sex, increasing age, comorbidity, and open surgery are risk factors for mortality, as is a lung diffusing capacity less than $50 \%$ of predicted (102, 104). (It is interesting to note that several of these risk factors substantially increase the clinical likelihood of IPF, and that "provisional diagnosis" of IPF prior to surgical lung biopsy was a risk factor for in-hospital mortality). (103) Complications include pneumothorax, pneumonia, prolonged air leak, acute exacerbations and infections $(105,106)$. The decision to perform surgical lung biopsy to make a diagnosis of UIP must be individualized based on risk factors and discussion with the patient.

Transbronchial cryobiopsy has recently emerged as a possible alternative to surgical lung biopsy with potentially lower morbidity and mortality (107-111) In this procedure, a cryoprobe cooled to -85 to -95 degrees Celsius is applied to the desired tissue. The resultant tissue specimen is substantially larger than a transbronchial forceps biopsy. However, cryobiopsies are significantly smaller than surgical lung biopsies (107) and this has implications in terms of diagnostic rate: up to $80 \%$ for the former and greater than 95\% for the latter.(110) Additionally, cryobiopsies are usually obtained from a more central site (away from pleural surface), and this may further reduce the diagnostic yield for IPF. Even if multiple samples are obtained, they are usually obtained from the same site (107). The diagnostic yield and complication rate is variable and depend on the experience of the operator. At present there is greater experience with this technique in Europe than in the rest of the world. The role of transbronchial cryobiopsy in fibrotic ILD remains unclear given the uneven experience around the world, the need for clearer standardization of the technique and the need to establish that the safety profile remains acceptable in less experienced hands. Surgical biopsy remains the gold standard for tissue diagnosis. 
What are the critical pathologic features that can be used to make the diagnosis of UIP/IPF?

IPF is pathologically characterized by a UIP pattern; however, UIP can also be seen in other settings including CTD, HP, drug toxicity, and pneumoconiosis. For this reason, the terminology UIP/IPF is used in this document to distinguish the UIP pattern in IPF from UIP occurring in other conditions. The major pathologic features of UIP include: 1) dense fibrosis causing remodeling of lung architecture with frequent honeycomb fibrosis, 2) fibroblast foci typically scattered at the edges of dense scars, 3) patchy lung involvement and 4) frequent subpleural, paraseptal and peripheral acinar distribution (Figure 7, Table 4). Specific pertinent findings should be absent, including diffuse alveolar damage (DAD), organizing pneumonia (OP), hypersensitivity pneumonitis, airway centered processes, and granulomatous inflammation. One exception is in acute exacerbation of UIP/IPF, in which prominent hyaline membranes of diffuse alveolar damage and organizing pneumonia may be superimposed on a UIP pattern.

Honeycombing (Figure 8) is one of the key findings both pathologically and radiologically in IPF although its presence is not required for the diagnosis. Both radiologic and pathologic honeycombing is defined by the presence of abnormal airspaces; however, the pathologic definition applies to airspaces from microscopic honeycombing (beyond the resolution of CT) to cysts larger than a centimeter (112), whereas the radiologic definition applies to abnormal airspaces typically $3-5 \mathrm{~mm}$ in size (51). While there is obvious overlap in these definitions, radiologic honeycombing should not be equated with pathologic honeycombing $(54,68)$ 


\section{How can UIP/IPF be distinguished histologically from other fibrosing interstitial}

\section{pneumonias?}

The most common entities to be distinguished from IPF include chronic HP, $(2,113-115)$ idiopathic NSIP, $(58,116)$ CTD, and pleuroparenchymal fibroelastosis (PPFE).(67, 117) HP typically shows bronchiolocentricity, cellular interstitial chronic inflammation, poorly formed granulomas, organizing pneumonia, and, in more chronic disease, it can show fibrosis, including a UIP pattern (Figure 9). Pathologically, NSIP is characterized by uniform thickening of alveolar walls by fibrosis and/or chronic inflammation without honeycombing and either absent or inconspicuous fibroblast foci. The fibrosis in PPFE is predominantly in the upper lobes and shows an intra-alveolar fibrosis with prominent elastosis in the alveolar interstitium, but can coexist with UIP and other patterns of interstitial fibrosis. $(67,117)$ UIP associated with CTD can show coexistent features including pleuritis, organizing pneumonia, prominent interstitial chronic inflammation and/or lymphoid hyperplasia including follicular bronchiolitis (Figure 10). $(68,118,119)$

Most patients with IPF have a previous or current history of smoking cigarettes, and smoking-related changes may coexist with and complicate the histopathology of UIP in IPF. These changes include emphysema, sometimes associated with scarring, airspace enlargement with fibrosis,(120) respiratory bronchiolitis which itself may be associated with ILD (RB-ILD),(121, 122) respiratory bronchiolitis with fibrosis,$(123,124)$ subpleural hyaline alveolar septal scarring, sometimes stellate and centrilobular (smoking related interstitial fibrosis), desquamative interstitial pneumonia (DIP) with fibrosis, and a pattern that can be described as fibrotic NSIP in a smoker, resembling DIP fibrosis absent the airspace macrophages, that has been called smoking related IIP.(125) 


\section{Histologic Diagnostic Categories}

A table in the 2011 ATS/ERS/JRS/ALAT IPF management guidelines proposed criteria for "Definite", "Probable", "Possible" and "Definitely not UIP" that could be correlated with imaging as part of a diagnostic algorithm.(1). However, these criteria do not take into account the increasing recognition of a UIP pattern occurring in diseases other than IPF, such as chronic HP and CTD. A revised version is therefore proposed in which criteria are more specifically related to UIP arising in patients with IPF (i.e., "UIP/IPF") (Table 4). In the possible and indeterminate categories, it is important to provide a descriptive diagnosis, listing the various diagnostic considerations.

\section{Guidance for multidisciplinary diagnosis (MDD)}

MDD is performed in the evaluation of fibrotic ILD to establish the diagnosis and level of diagnostic confidence, to determine the need for biopsy and other investigations, and to help guide management. In the 2011 ATS/ERS/JRS/ALAT guideline for the diagnosis and management of IPF, "multidisciplinary diagnosis" (MDD) consisted of the integration of views from radiologists, pathologists and pulmonary specialists, primarily based on a formulaic tabulated approach. However, the process of MDD is increasingly viewed as synonymous with diagnosis by means of interactive multidisciplinary discussion, an approach that has been shown to be effective in other disciplines (126). In fibrotic ILD, multiple papers have shown that inter-observer agreement among clinicians, radiologists and pathologists increases substantially following MDD, with increase in diagnostic confidence and a change in the histologic diagnosis in up to $20 \%$ of subjects $(127,128)$. In a recent single-center study, a prior diagnosis of IPF was deemed inaccurate after MDD in over $50 \%$ of cases (129). In a second study, MDD resulted in a change in diagnosis in 10 of 27 patients referred with a diagnosis of IPF, while 7 patients referred with non-IPF diagnoses had their diagnosis changed to IPF (130). 
A major advantage of MDD that it reduces diagnostic imprecision due to recognized limitations in each of the three domains, although the accuracy of each domain is heavily influenced by individual experience of the clinician, radiologist, and pathologist. Uneven levels of experience within a group may create a hierarchy of opinion with the result that a single participant may dominate the process, to the detriment of interactive group discussion. However, lack of experience by a single individual is an even greater problem when diagnosis is based on a single domain, without interactive discussion. The MD forum also facilitates weighting of data that provide clear diagnostic guidance on a case-by-case basis, minimizing the uncertainty caused by clinical, radiologic, or histologic information that is difficult to classify. Although MDD has multiple advantages and is widely regarded as the current diagnostic reference standard in IPF, it has not been formally validated. One major difficulty is that all diagnostic information, against which the accuracy of MDD might be examined is, by definition, included in the MDD.

Consistency of MDD between expert groups requires international consensus agreement on diagnostic criteria, which is conspicuously absent for many of the alternative entities in the differential diagnosis of IPF. In a recent study in which seven expert multidisciplinary groups evaluated the same patient data, agreement on IPF as a first choice diagnosis was good (weighted kappa=0.71) but there was poor agreement on the diagnosis of chronic HP $(\mathrm{K}=0.24)$ and idiopathic NSIP $(\mathrm{K}=0.25)$. This discrepancy probably reflects the international, multidisciplinary work that has gone into establishing diagnostic criteria for IPF, whereas no such initiatives have focused on HP or idiopathic NSIP. Accepting this limitation, our consensus is that MDD should be viewed as the current method of IPF diagnosis in several specific contexts (see Table 6). 
The MDD process should incorporate standardized data applicable to all patients. As part of the process it should be able to address a) atypical features which lie outside classical clinical, CT, or histologic patterns; and b) non-standardized information which varies from case to case. For example, a definite IPF diagnosis requires the correct clinical context and the presence of a UIP pattern on CT; however, it is often necessary to reconcile atypical features and to integrate additional non-standard information such as bronchoalveolar lavage findings (not performed at all centers), subtle clinical and serologic features suggestive of immune dysregulation, and, perhaps most importantly, information on the natural history and/or treated course of disease ("disease behavior"). In many cases, a definite diagnosis cannot be made, but a highly probable "working diagnosis" can be achieved. Thus, MDD is essentially a process by which the existing evidence base is combined with clinical reasoning to increase or decrease the likelihood of an IPF diagnosis. Specialists engaged in MDD have two important roles: to serve as expert representatives of their disciplines and, equally importantly, to scrutinize and debate the logic of clinical reasoning, when this is required.

With this background, the committee identified the following key features of the MDD process. 1) Not all patients with IPF require MDD. For example, there is no need for discussion in patients with classical CT features of IPF in the correct clinical context if the patient has been reviewed by a single experienced radiologist and clinician. MDD exists to categorize patients who are not adequately characterized by the existing evidence base. MDD is particularly helpful in the following contexts: a) to decide whether to perform biopsy if imaging and/or clinical features do not provide an adequate level of diagnostic confidence; b) to review the clinical, imaging, and pathologic features after a biopsy has been performed; and c) to re-review cases where the longitudinal course is discordant with the clinical 
diagnosis. In suspected IPF, the goal of MDD is to establish or disprove the diagnosis with the highest level of confidence possible.

2) Minimum participants consist of a single clinician, radiologist and pathologist with appropriate levels of experience in ILD diagnosis. The opinion of a rheumatologist with regard to the likelihood of connective tissue disease is often valuable. Other medical specialists (e.g. occupational physicians, geneticists) may be helpful in specific cases. Whilst face-to-face discussion in a public forum is ideal, this is often impracticable for practitioners and patients not seen at expert centers. Telemedicine is an acceptable alternative.

3) Diagnosis should be clearly communicated by indicating whether formal IPF diagnostic criteria were satisfied or whether clinical reasoning was required to produce a working diagnosis. In the latter scenario, the confidence of the working diagnosis should be declared as "established" or "provisional with high or low confidence". (131)

\section{Areas of uncertainty}

Our current understanding of the diagnosis of IPF has many important gaps, and diagnostic guidelines will require regular revision. In this regard, several groups are working on combining imaging and clinical features to define the probability of IPF. $(11,132)$ The clinical significance of atypical features on CT (e.g., mosaic attenuation, apical pleuropulmonary thickening) or on biopsy (e.g., granulomas pleuropulmonary fibroelastosis) requires further clarification. More work is needed to understand the specificity of CT features that suggest a non-IPF alternative diagnosis (e.g. upper lobe-predominance, subpleural sparing, consolidation, predominant ground glass opacity). Further studies of cryobiopsy and correlation with surgical biopsy and outcome should clarify the role of this technique in diagnosis of IPF. 
We anticipate that molecular diagnosis with machine learning will play an increasing role in the diagnosis of IPF, particularly when integrated with clinical and imaging features. $(133,134)$ Finally, given the high prevalence of "early interstitial lung abnormality" on CT scans performed for other reasons, $(135,136)$ and the clear association with increased mortality in these individuals, (137) identification of clinical, radiologic and molecular predictors of IPF in this group will be critical.

\section{Conclusions and recommendations}

The clinical, imaging, and histologic criteria for diagnosis of IPF continue to evolve. Table 6 provides some diagnostic parameters that may be followed in patients with suspected IPF, based on clinical diagnostic confidence, and the radiologic and pathologic categories discussed above. The diagnosis of IPF may be confidently made in a patient with a typical clinical context of IPF, with a CT pattern of definite or probable UIP. In all other circumstances, multidisciplinary diagnosis is appropriate to inform the decision to proceed with biopsy or other diagnostic evaluation. Multidisciplinary assessment may yield a working diagnosis of IPF in some situations that do not meet all criteria, particularly if diagnostic tissue is not available. However, such a diagnosis may change over time, for example if a CTD becomes apparent, or a previously unrecognized exposure is identified. We hope that the scheme outlined in this document will contribute to diagnostic clarity and help improve the management of patients with fibrotic lung diseases. 


\section{Figure legends}

Figure 1

Typical UIP CT pattern: Axial and coronal CT images (Figs 1a-e) show subpleural predominant reticular abnormality with traction bronchiectasis and honeycombing, with a clear craniocaudal gradient. on coronal images. A magnified view of a different patient (Figure 1f) shows areas of honeycombing occurring in single and multiple layers (arrows). Additionally, two areas of apparent ground glass abnormality (circles) are shown on closer inspection to contain dilated bronchi (traction bronchiectasis), and therefore likely to represent fibrosis.

\section{Figure 2}

Probable UIP CT pattern: CT shows basal predominantsubpleural predominant reticular abnormality with peripheral traction bronchiectasis (circles, Fig $2 \mathrm{~b}$ ) but no honeycombing. UIP was proven at histology.

\section{Figure 3}

CT pattern indeterminate for UIP: CT shows reticular abnormality with traction bronchiectasis, without honeycombing. Although the abnormality is lower lung predominant, the findings are not typical for UIP because of peribronchovascular extension (Figure 3c), patchy ground glass abnormality and mosaic attenuation (Figure 3e). UIP was proven at biopsy.

\section{Figure 4}


CT pattern indeterminate for UIP: inspiratory CT shows diffuse, peripheral predominant reticular opacities admixed with patchy areas of decreased (mosaic) attenuation (arrows). UIP was proven at biopsy.

\section{Figure 5}

CT pattern most consistent with non-IPF diagnosis: inspiratory CT shows upper lobe predominant peribronchovascular (bronchocentric) reticular opacities, architectural distortion, and severe traction bronchiectasis, associated with areas of decreased attenuation (arrows). This CT pattern is consistent with fibrotic hypersensitivity pneumonitis.

\section{Figure 6}

Fibroblastic focus

Fibroblast foci in UIP/IPF sometimes are highlighted by their basophilic appearance reflective of increased mucopolysaccharide associated with young fibrous tissue. The fibroblast foci (arrows) show prominent basophilia and again are rounded to convex in configuration and adjacent to dense scarring.

\section{Figure 7}

Definite UIP

Scanning power microscopy shows patchy subpleural and paraseptal scarring that includes some subpleural microscopic honeycombing (a, arrows). Higher power evaluation from the same case shows readily identifiable fibroblast foci ( $b$ and $c$, arrows). The fibroblast foci are pale and edematous and somewhat convex/rounded in appearance and adjacent to scarring. Such a case fulfills criteria for definite UIP/IPF. 
Figure 8

Probable UIP

Scanning power microscopy shows that the sampled tissue is entirely replaced by honeycomb change.

Such a biopsy, in the appropriate clinical setting, is designated probable UIP/IPF.

\section{Figure 9}

Suggestive of an alternative diagnosis: Chronic HP

Some regions show typical scanning power appearance of UIP with peripheral and subpleural scarring

(a) and readily identifiable fibroblast foci (b, arrow). Other fields in the same case, however, show centrilobular injury (c) with associated organizing pneumonia and small non-necrotizing granulomas (d, arrow) characteristic of HP.

\section{Figure 10}

UIP in Connective tissue disease

This biopsy from a patient with rheumatoid arthritis and interstitial lung disease shows honeycomb change with prominent lymphoid hyperplasia with germinal centers, the latter being a clue to an underlying connective tissue disease. However, a few lymphoid follicles, including a rare germinal center, are not uncommon in UIP/IPF. Fibroblast foci were present in the regions of honeycombing in this case (b, center). 


\section{References}

1. Raghu G, Collard HR, Egan JJ, Martinez FJ, Behr J, Brown KK, et al. An official ATS/ERS/JRS/ALAT statement: idiopathic pulmonary fibrosis: evidence-based guidelines for diagnosis and management. Am J Respir Crit Care Med. 2011 Mar 15;183(6):788-824.

2. de Andrade J, Schwarz M, Collard HR, Gentry-Bumpass T, Colby T, Lynch D, et al. The Idiopathic Pulmonary Fibrosis Clinical Research Network (IPFnet): diagnostic and adjudication processes. Chest. 2015 Oct;148(4):1034-42.

3. Richeldi L, du Bois RM, Raghu G, Azuma A, Brown KK, Costabel U, et al. Efficacy and Safety of Nintedanib in Idiopathic Pulmonary Fibrosis. N Engl J Med. 2014 May 18.

4. King TE, Jr., Bradford WZ, Castro-Bernardini S, Fagan EA, Glaspole I, Glassberg MK, et al. A phase 3 trial of pirfenidone in patients with idiopathic pulmonary fibrosis. N Engl J Med. 2014 May 29;370(22):2083-92.

5. Martinez FJ, de Andrade JA, Anstrom KJ, King TE, Jr., Raghu G. Randomized trial of acetylcysteine in idiopathic pulmonary fibrosis. N Engl J Med. 2014 May 29;370(22):2093-101.

6. Idiopathic Pulmonary Fibrosis Clinical Research N, Raghu G, Anstrom KJ, King TE, Jr., Lasky JA, Martinez FJ. Prednisone, azathioprine, and N-acetylcysteine for pulmonary fibrosis. N Engl J Med. 2012 May 24;366(21):1968-77.

7. Idiopathic Pulmonary Fibrosis Clinical Research N, Zisman DA, Schwarz M, Anstrom KJ, Collard $\mathrm{HR}$, Flaherty KR, et al. A controlled trial of sildenafil in advanced idiopathic pulmonary fibrosis. $\mathrm{N}$ Engl J Med. 2010 Aug 12;363(7):620-8.

8. Raghu G, Lynch D, Godwin JD, Webb R, Colby TV, Leslie KO, et al. Diagnosis of idiopathic pulmonary fibrosis with high-resolution $\mathrm{CT}$ in patients with little or no radiological evidence of honeycombing: secondary analysis of a randomised, controlled trial. Lancet Respir Med. 2014 Apr;2(4):277-84.

9. Raghu G, Wells AU, Nicholson AG, Richeldi L, Flaherty KR, Le Maulf F, et al. Effect of Nintedanib in Subgroups of Idiopathic Pulmonary Fibrosis by Diagnostic Criteria. Am J Respir Crit Care Med. 2017 Jan 01;195(1):78-85.

10. Yagihashi K, Huckleberry J, Colby TV, Tazelaar HD, Zach J, Sundaram B, et al. Radiologicpathologic discordance in biopsy-proven usual interstitial pneumonia. Eur Respir J. 2016 Apr;47(4):118997.

11. Brownell R, Moua T, Henry TS, Elicker BM, White D, Vittinghoff E, et al. The use of pretest probability increases the value of high-resolution $\mathrm{CT}$ in diagnosing usual interstitial pneumonia. Thorax. 2017 May;72(5):424-9.

12. Vij R, Noth I, Strek ME. Autoimmune-featured interstitial lung disease: a distinct entity. Chest. 2011 Nov;140(5):1292-9.

13. Corte TJ, Copley SJ, Desai SR, Zappala CJ, Hansell DM, Nicholson AG, et al. Significance of connective tissue disease features in idiopathic interstitial pneumonia. Eur Respir J. 2012 Mar;39(3):6618.

14. Kinder BW, Collard HR, Koth L, Daikh DI, Wolters PJ, Elicker B, et al. Idiopathic nonspecific interstitial pneumonia: lung manifestation of undifferentiated connective tissue disease? Am J Respir Crit Care Med. 2007 Oct 1;176(7):691-7. 
15. Fischer A, Antoniou KM, Brown KK, Cadranel J, Corte TJ, du Bois RM, et al. An official European Respiratory Society/American Thoracic Society research statement: interstitial pneumonia with autoimmune features. Eur Respir J. 2015 Jul 9.

16. Ahmad K, Barba T, Gamondes D, Ginoux M, Khouatra C, Spagnolo P, et al. Interstitial pneumonia with autoimmune features: Clinical, radiologic, and histological characteristics and outcome in a series of 57 patients. Respir Med. 201701 Feb;123:56-62.

17. Alhamad EH, Cal JG, AlBoukai AA, Shaik SA, Omair MA, Alhamad EH, et al. Autoimmune symptoms in idiopathic pulmonary fibrosis: clinical significance. 2016:350-8, 2016 May.

18. Chung JH, Montner SM, Adegunsoye A, Lee C, Oldham JM, Husain AN, et al. CT Findings, Radiologic-Pathologic Correlation, and Imaging Predictors of Survival for Patients With Interstitial Pneumonia With Autoimmune Features. AJR Am J Roentgenol. 2017 Mar 28:1-8.

19. Selman M. Hypersensitivity pneumonitis. In: Schwarz MI, King TE, Jr., editors. Interstitial lung disease. Shelton, CT: People's Medical Publishing House; 2011. p. 589-99.

20. Lacasse Y, Selman M, Costabel U, Dalphin JC, Ando M, Morell F, et al. Clinical diagnosis of hypersensitivity pneumonitis. Am J Respir Crit Care Med. 2003 Oct 15;168(8):952-8.

21. Fernández Pérez ER, Swigris JJ, Forssén AV, Tourin O, Solomon JJ, Huie TJ, et al. Identifying an Inciting Antigen Is Associated With Improved Survival in Patients With Chronic Hypersensitivity Pneumonitis. Chest. 2013 2013/11/01/;144(5):1644-51.

22. Mooney JJ, Elicker BM, Urbania TH, Agarwal MR, Ryerson CJ, Nguyen MLT, et al. Radiographic fibrosis score predicts survival in hypersensitivity pneumonitis. Chest. 2013 Aug;144(2):586-92.

23. Chan AL, Juarez MM, Leslie KO, Ismail HA, Albertson TE. Bird Fancier's Lung: A State-of-the-Art Review. Clin Rev Allergy Immunol. 2012;43(1):69-83.

24. Kouranos V, Jacob J, Nicholson A, Renzoni E. Fibrotic Hypersensitivity Pneumonitis: Key Issues in Diagnosis and Management. Journal of clinical medicine. 2017 Jun 15;6(6).

25. Welker $L$, Jorres RA, Costabel $U$, Magnussen $H$. Predictive value of BAL cell differentials in the diagnosis of interstitial lung diseases. Eur Respir J. 2004 Dec;24(6):1000-6.

26. Meyer KC, Raghu G, Baughman RP, Brown KK, Costabel U, du Bois RM, et al. An official American Thoracic Society clinical practice guideline: the clinical utility of bronchoalveolar lavage cellular analysis in interstitial lung disease. Am J Respir Crit Care Med. 2012 May 01;185(9):1004-14.

27. Foucher P, Camus P. The drug-induced lung diseases. 2017 [May 3, 2017]; Available from: http://pneumotox.com/.

28. Brichet A, Tonnel AB, Brambilla E, Devouassoux G, Remy-Jardin M, Copin MC, et al. Chronic interstitial pneumonia with honeycombing in coal workers. Sarcoidosis Vasc Diffuse Lung Dis. 2002 Oct;19(3):211-9.

29. Katabami M, Dosaka-Akita H, Honma K, Saitoh Y, Kimura K, Uchida Y, et al. Pneumoconiosisrelated lung cancers: preferential occurrence from diffuse interstitial fibrosis-type pneumoconiosis. Am J Respir Crit Care Med. 2000;162:295-300.

30. Honma K, Chiyotani K. Diffuse interstitial fibrosis in nonasbestos pneumoconiosis--a pathological study. Respiration. 1993;60(2):120-6.

31. Copley SJ, Wells AU, Sivakumaran P, Rubens MB, Lee YC, Desai SR, et al. Asbestosis and idiopathic pulmonary fibrosis: comparison of thin-section CT features. Radiology. 2003 Dec;229(3):7316.

32. Akira M, Morinaga K. The comparison of high-resolution computed tomography findings in asbestosis and idiopathic pulmonary fibrosis. Am J Ind Med. 2016 Apr;59(4):301-6. 
33. Akira M, Yamamoto S, Inoue $Y$, Sakatani M. High-resolution CT of asbestosis and idiopathic pulmonary fibrosis. AJR Am J Roentgenol. 2003 Jul;181(1):163-9.

34. Mathai SK, Newton CA, Schwartz DA, Garcia CK. Pulmonary fibrosis in the era of stratified medicine. Thorax. 2016 Oct 31.

35. Lee HY, Seo JB, Steele MP, Schwarz MI, Brown KK, Loyd JE, et al. High-resolution CT scan findings in familial interstitial pneumonia do not conform to those of idiopathic interstitial pneumonia. Chest. 2012 Dec;142(6):1577-83.

36. Steele MP, Speer MC, Loyd JE, Brown KK, Herron A, Slifer SH, et al. Clinical and pathologic features of familial interstitial pneumonia. Am J Respir Crit Care Med. 2005 Nov 01;172(9):1146-52.

37. Mayo JR. CT evaluation of diffuse infiltrative lung disease: dose considerations and optimal technique. Journal of thoracic imaging. 2009 Nov;24(4):252-9.

38. Bankier AA, O'Donnell CR, Boiselle PM. Quality initiatives. Respiratory instructions for CT examinations of the lungs: a hands-on guide. Radiographics : a review publication of the Radiological Society of North America, Inc. 2008 Jul-Aug;28(4):919-31.

39. Remy-Jardin M, Campistron P, Amara A, Mastora I, Tillie-Leblond I, Delannoy V, et al. Usefulness of coronal reformations in the diagnostic evaluation of infiltrative lung disease. Journal of computer assisted tomography. 2003 Mar-Apr;27(2):266-73.

40. Johkoh T, Sakai F, Noma S, Akira M, Fujimoto K, Watadani T, et al. Honeycombing on CT; its definition, pathologic correlation, and future direction of its diagnosis. Eur J Radiol. 2014 Jan;83(1):27-

31.

41. Bankier AA, Tack D. Dose reduction strategies for thoracic multidetector computed tomography: background, current issues, and recommendations. J Thorac Imaging. 2010 Nov;25(4):278-88.

42. Pontana F, Billard AS, Duhamel A, Schmidt B, Faivre JB, Hachulla E, et al. Effect of Iterative Reconstruction on the Detection of Systemic Sclerosis-related Interstitial Lung Disease: Clinical Experience in 55 Patients. Radiology. 2016 Apr;279(1):297-305.

43. Hansell DM. Thin-section CT of the lungs: the Hinterland of normal. Radiology. 2010 Sep;256(3):695-711.

44. Kim M, Lee SM, Song JW, Do KH, Lee HJ, Lim S, et al. Added value of prone CT in the assessment of honeycombing and classification of usual interstitial pneumonia pattern. Eur J Radiol. 2017 Jun;91:6670.

45. Tokura S, Okuma T, Akira M, Arai T, Inoue Y, Kitaichi M. Utility of expiratory thin-section CT for fibrotic interstitial pneumonia. Acta Radiol. 2014 Nov;55(9):1050-5.

46. Gotway MB, Lee ES, Reddy GP, Golden JA, Webb WR. Low-dose, dynamic, expiratory thinsection CT of the lungs using a spiral CT scanner. J Thorac Imaging. 2000 Jul;15(3):168-72.

47. Wells AU, Hansell DM, Rubens MB, Cullinan P, Black CM, du Bois RM. The predictive value of appearances on thin-section computed tomography in fibrosing alveolitis. Am Rev Respir Dis. 1993;148:1076-82.

48. Lynch DA, Godwin JD, Safrin S, Starko KM, Hormel P, Brown KK, et al. High-resolution computed tomography in idiopathic pulmonary fibrosis: diagnosis and prognosis. Am J Respir Crit Care Med. 2005;172:488-93.

49. Sumikawa H, Johkoh T, Colby TV, Ichikado K, Suga M, Taniguchi H, et al. Computed tomography findings in pathological usual interstitial pneumonia: relationship to survival. Am J Respir Crit Care Med. 2008 Feb 15;177(4):433-9. 
50. Shin KM, Lee KS, Chung MP, Han J, Bae YA, Kim TS, et al. Prognostic determinants among clinical, thin-section $\mathrm{CT}$, and histopathologic findings for fibrotic idiopathic interstitial pneumonias: tertiary hospital study. Radiology. 2008 Oct;249(1):328-37.

51. Hansell DM, Bankier AA, MacMahon H, McLoud TC, Muller NL, Remy J. Fleischner Society: glossary of terms for thoracic imaging. Radiology. 2008 Mar;246(3):697-722.

52. Jacob J, Hansell DM. HRCT of fibrosing lung disease. Respirology. 2015 Aug;20(6):859-72.

53. Staats P, Kligerman S, Todd N, Tavora F, Xu L, Burke A. A comparative study of honeycombing on high resolution computed tomography with histologic lung remodeling in explants with usual interstitial pneumonia. Pathol Res Pract. 2015 Jan;211(1):55-61.

54. Chung JH, Chawla A, Peljto AL, Cool CD, Groshong SD, Talbert JL, et al. CT scan findings of probable usual interstitial pneumonitis have a high predictive value for histologic usual interstitial pneumonitis. Chest. 2015 Feb;147(2):450-9.

55. Mai C, Verleden SE, McDonough JE, Willems S, De Wever W, Coolen J, et al. Thin-Section CT Features of Idiopathic Pulmonary Fibrosis Correlated with Micro-CT and Histologic Analysis. Radiology. 2017 Apr;283(1):252-63.

56. Watadani T, Sakai F, Johkoh T, Noma S, Akira M, Fujimoto K, et al. Interobserver variability in the CT assessment of honeycombing in the lungs. Radiology. 2013 Mar;266(3):936-44.

57. Edey AJ, Devaraj AA, Barker RP, Nicholson AG, Wells AU, Hansell DM. Fibrotic idiopathic interstitial pneumonias: HRCT findings that predict mortality. Eur Radiol. 2011 Aug;21(8):1586-93.

58. Travis WD, Hunninghake G, King TE, Jr., Lynch DA, Colby TV, Galvin JR, et al. Idiopathic nonspecific interstitial pneumonia: report of an American Thoracic Society project. Am J Respir Crit Care Med. 2008 Jun 15;177(12):1338-47.

59. Piciucchi S, Tomassetti S, Ravaglia C, Gurioli C, Gurioli C, Dubini A, et al. From "traction bronchiectasis" to honeycombing in idiopathic pulmonary fibrosis: A spectrum of bronchiolar remodeling also in radiology? 2016:87, 2016 May 23.

60. Walsh SL, Sverzellati N, Devaraj A, Keir GJ, Wells AU, Hansell DM. Connective tissue disease related fibrotic lung disease: high resolution computed tomographic and pulmonary function indices as prognostic determinants. Thorax. 2014 Mar;69(3):216-22.

61. Remy-Jardin M, Giraud F, Remy J, Copin MC, Gosselin B, Duhamel A. Importance of ground-glass attenuation in chronic diffuse infiltrative lung disease: pathologic-CT correlation. Radiology. 1993;189(3):693-8.

62. Akira M, Kozuka T, Yamamoto S, Sakatani M. Computed tomography findings in acute exacerbation of idiopathic pulmonary fibrosis. Am J Respir Crit Care Med. 2008 Aug 15;178(4):372-8.

63. Kim DS, Park JH, Park BK, Lee JS, Nicholson AG, Colby T. Acute exacerbation of idiopathic pulmonary fibrosis: frequency and clinical features. Eur Respir J. 2006 Jan;27(1):143-50.

64. Souza CA, Müller NL, Lee KS, Johkoh T, Mitsuhiro H, Chong S. Idiopathic interstitial pneumonias: prevalence of mediastinal lymph node enlargement in 206 patients. AJR Am J Roentgenol. 2006 Apr;186(4):995-9.

65. Kim TS, Han J, Chung MP, Chung MJ, Choi YS. Disseminated dendriform pulmonary ossification associated with usual interstitial pneumonia: incidence and thin-section CT-pathologic correlation. Eur Radiol. 2005 Aug;15(8):1581-5.

66. Egashira R, Jacob J, Kokosi MA, Brun AL, Rice A, Nicholson AG, et al. Diffuse Pulmonary Ossification in Fibrosing Interstitial Lung Diseases: Prevalence and Associations. Radiology. 2017 Feb 09:152419. 
67. Reddy TL, Tominaga M, Hansell DM, von der Thusen J, Rassl D, Parfrey H, et al.

Pleuroparenchymal fibroelastosis: a spectrum of histopathological and imaging phenotypes. Eur Respir J. 2012 Aug;40(2):377-85.

68. Song JW, Do KH, Kim MY, Jang SJ, Colby TV, Kim DS. Pathologic and radiologic differences between idiopathic and collagen vascular disease-related usual interstitial pneumonia. Chest. 2009 Jul;136(1):23-30.

69. Padley SP, Padhani AR, Nicholson A, Hansell DM. Pulmonary sarcoidosis mimicking cryptogenic fibrosing alveolitis on CT. Clin Radiol. 1996;51(11):807-10.

70. Mejia M, Carrillo G, Rojas-Serrano J, Estrada A, Suarez T, Alonso D, et al. Idiopathic pulmonary fibrosis and emphysema: decreased survival associated with severe pulmonary arterial hypertension. Chest. 2009 Jul;136(1):10-5.

71. Mura M, Zompatori M, Pacilli AM, Fasano L, Schiavina M, Fabbri M. The presence of emphysema further impairs physiologic function in patients with idiopathic pulmonary fibrosis. Respir Care. 2006 Mar;51(3):257-65.

72. Akira M, Inoue $\mathrm{Y}$, Kitaichi M, Yamamoto S, Arai T, Toyokawa K. Usual interstitial pneumonia and nonspecific interstitial pneumonia with and without concurrent emphysema: thin-section CT findings. Radiology. 2009 Apr;251(1):271-9.

73. Cottin V. The impact of emphysema in pulmonary fibrosis. Eur Respir Rev. 2013 Jun 01;22(128):153-7.

74. Travis WD, Costabel U, Hansell DM, King TE, Jr., Lynch DA, Nicholson AG, et al. An official American Thoracic Society/European Respiratory Society statement: Update of the international multidisciplinary classification of the idiopathic interstitial pneumonias. Am J Respir Crit Care Med. 2013 Sep 15;188(6):733-48.

75. Yamada T, Nakanishi Y, Homma T, Uehara K, Mizutani T, Hoshi E, et al. Airspace enlargement with fibrosis shows characteristic histology and immunohistology different from usual interstitial pneumonia, nonspecific interstitial pneumonia and centrilobular emphysema. Pathol Int. 2013 Apr;63(4):206-13.

76. Watanabe Y, Kawabata Y, Kanauchi T, Hoshi E, Kurashima K, Koyama S, et al. Multiple, thinwalled cysts are one of the HRCT features of airspace enlargement with fibrosis. Eur J Radiol. 2015 May;84(5):986-92.

77. Inomata M, Ikushima S, Awano N, Kondoh K, Satake K, Masuo M, et al. An autopsy study of combined pulmonary fibrosis and emphysema: correlations among clinical, radiological, and pathological features. BMC Pulm Med. 2014 Jun 28;14:104.

78. Silva Cl, Müller NL, Lynch DA, Curran-Everett D, Brown KK, Lee KS, et al. Chronic hypersensitivity pneumonitis: differentiation from idiopathic pulmonary fibrosis and nonspecific interstitial pneumonia by using thin-section CT. Radiology. 2008 Jan;246(1):288-97.

79. Sahin H, Brown KK, Curran-Everett D, Hale V, Cool CD, Vourlekis JS, et al. Chronic hypersensitivity pneumonitis: CT features comparison with pathologic evidence of fibrosis and survival. Radiology. 2007 Aug;244(2):591-8.

80. Hwang JH, Misumi S, Sahin H, Brown KK, Newell JD, Lynch DA. Computed tomographic features of idiopathic fibrosing interstitial pneumonia: comparison with pulmonary fibrosis related to collagen vascular disease. J Comput Assist Tomogr. 2009 May-Jun;33(3):410-5.

81. Sverzellati N, Wells AU, Tomassetti S, Desai SR, Copley SJ, Aziz ZA, et al. Biopsy-proved idiopathic pulmonary fibrosis: spectrum of nondiagnostic thin-section CT diagnoses. Radiology. 2010 Mar;254(3):957-64. 
82. Sumikawa $\mathrm{H}$, Johkoh $\mathrm{T}$, Ichikado $\mathrm{K}$, Taniguchi $\mathrm{H}$, Kondoh $\mathrm{Y}$, Fujimoto $\mathrm{K}$, et al. Usual interstitial pneumonia and chronic idiopathic interstitial pneumonia: analysis of $\mathrm{CT}$ appearance in 92 patients. Radiology. 2006 Oct;241(1):258-66.

83. Le Rouzic O, Bendaoud S, Chenivesse C, Remy J, Wallaert B. Prognostic value of the initial chest high-resolution CT pattern in idiopathic pulmonary fibrosis. Sarcoidosis Vasculitis \& Diffuse Lung Diseases. 2016 Jan 18;32(4):353-9.

84. Romei C, Tavanti L, Sbragia P, De Liperi A, Carrozzi L, Aquilini F, et al. Idiopathic interstitial pneumonias: do HRCT criteria established by ATS/ERS/JRS/ALAT in 2011 predict disease progression and prognosis? Radiologia Medica. 2015 Oct;120(10):930-40.

85. Lee JW, Shehu E, Gjonbrataj J, Bahn YE, Rho BH, Lee MY, et al. Clinical findings and outcomes in patients with possible usual interstitial pneumonia. Respir Med. 2015 Apr;109(4):510-6.

86. Walsh SL, Calandriello L, Sverzellati N, Wells AU, Hansell DM, Consort UIPO. Interobserver agreement for the ATS/ERS/JRS/ALAT criteria for a UIP pattern on CT. Thorax. 2016 Jan;71(1):45-51.

87. Hunninghake GW, Lynch DA, Galvin JR, Gross BH, Müller N, Schwartz DA, et al. Radiologic findings are strongly associated with a pathologic diagnosis of usual interstitial pneumonia. Chest. 2003 Oct;124(4):1215-23.

88. Hunninghake GW, Zimmerman MB, Schwartz DA, King TE, Lynch J, Hegele R, et al. Utility of a lung biopsy for the diagnosis of idiopathic pulmonary fibrosis. Am J Respir Crit Care Med. 2001;164(2):193-6.

89. Gruden JF, Panse PM, Leslie KO, Tazelaar HD, Colby TV. UIP diagnosed at surgical lung biopsy, 2000-2009: HRCT patterns and proposed classification system. AJR Am J Roentgenol. 2013 May;200(5):W458-67.

90. Gruden JF, Panse PM, Gotway MB, Jensen EA, Wellnitz CV, Wesselius L. Diagnosis of Usual Interstitial Pneumonitis in the Absence of Honeycombing: Evaluation of Specific CT Criteria With Clinical Follow-Up in 38 Patients. AJR American Journal of Roentgenology. 2016 Mar;206(3):472-80.

91. Tcherakian C, Cottin V, Brillet PY, Freynet O, Naggara N, Carton Z, et al. Progression of idiopathic pulmonary fibrosis: lessons from asymmetrical disease. Thorax. 2011 Mar;66(3):226-31.

92. Raghu G, Mageto YN, Lockhart D, Schmidt RA, Wood DE, Godwin JD. The accuracy of the clinical diagnosis of new-onset idiopathic pulmonary fibrosis and other interstitial lung disease: A prospective study. Chest. 1999;116(5):1168-74.

93. Fell CD, Martinez FJ, Liu LX, Murray S, Han MK, Kazerooni EA, et al. Clinical predictors of a diagnosis of idiopathic pulmonary fibrosis. Am J Respir Crit Care Med. 2010 Apr 15;181(8):832-7.

94. Tomassetti S, Cavazza A, Colby TV, Ryu JH, Nanni O, Scarpi E, et al. Transbronchial biopsy is useful in predicting UIP pattern. Respir Res. 2012;13:96.

95. Sheth JS, Belperio JA, Fishbein MC, Kazerooni EA, Lagstein A, Murray S, et al. Utility of Transbronchial vs Surgical Lung Biopsy in the Diagnosis of Suspected Fibrotic Interstitial Lung Disease. Chest. 2017 Feb;151(2):389-99.

96. Shim HS, Park MS, Park IK. Histopathologic findings of transbronchial biopsy in usual interstitial pneumonia. Pathol Int. 2010 May;60(5):373-7.

97. Berbescu EA, Katzenstein AL, Snow JL, Zisman DA. Transbronchial biopsy in usual interstitial pneumonia. Chest. 2006 May;129(5):1126-31.

98. Monaghan H, Wells AU, Colby TV, du Bois RM, Hansell DM, Nicholson AG. Prognostic implications of histologic patterns in multiple surgical lung biopsies from patients with idiopathic interstitial pneumonias. Chest. 2004 Feb;125(2):522-6. 
99. Flaherty KR, Travis WD, Colby TV, Toews GB, Kazerooni EA, Gross BH, et al. Histopathologic variability in usual and nonspecific interstitial pneumonias. Am J Respir Crit Care Med. 2001 Nov 1;164(9):1722-7.

100. Qureshi RA, Ahmed TA, Grayson AD, Soorae AS, Drakeley MJ, Page RD. Does lung biopsy help patients with interstitial lung disease? Eur J Cardiothorac Surg. 2002 Apr;21(4):621-6; discussion 6. 101. Kadokura M, Colby TV, Myers JL, Allen MS, Deschamps C, Trastek VF, et al. Pathologic comparison of video-assisted thoracic surgical lung biopsy with traditional open lung biopsy. J Thorac Cardiovasc Surg. 1995 Mar;109(3):494-8.

102. Hutchinson JP, McKeever TM, Fogarty AW, Navaratnam V, Hubbard RB. Surgical lung biopsy for the diagnosis of interstitial lung disease in England: 1997-2008. Eur Respir J. 2016 Nov;48(5):1453-61.

103. Hutchinson JP, Fogarty AW, McKeever TM, Hubbard RB. In-Hospital Mortality after Surgical Lung Biopsy for Interstitial Lung Disease in the United States. 2000 to 2011. Am J Respir Crit Care Med. 2016 May 15;193(10):1161-7.

104. Park JH, Kim DK, Kim DS, Koh Y, Lee SD, Kim WS, et al. Mortality and risk factors for surgical lung biopsy in patients with idiopathic interstitial pneumonia. Eur J Cardiothorac Surg. 2007 Jun;31(6):1115-9. 105. Luo Q, Han Q, Chen X, Xie J, Wu L, Chen R. The diagnosis efficacy and safety of video-assisted thoracoscopy surgery (VATS) in undefined interstitial lung diseases: a retrospective study. J Thorac Dis. 2013 Jun;5(3):283-8.

106. Plones T, Osei-Agyemang T, Elze M, Palade E, Wagnetz D, Loop T, et al. Morbidity and mortality in patients with usual interstitial pneumonia (UIP) pattern undergoing surgery for lung biopsy. Respir Med. 2013 Apr;107(4):629-32.

107. Johannson KA, Marcoux VS, Ronksley PE, Ryerson CJ. Diagnostic Yield and Complications of Transbronchial Lung Cryobiopsy for Interstitial Lung Disease. A Systematic Review and Metaanalysis. Ann Am Thorac Soc. 2016 Oct;13(10):1828-38.

108. Ravaglia C, Bonifazi M, Wells AU, Tomassetti S, Gurioli C, Piciucchi S, et al. Safety and Diagnostic Yield of Transbronchial Lung Cryobiopsy in Diffuse Parenchymal Lung Diseases: A Comparative Study versus Video-Assisted Thoracoscopic Lung Biopsy and a Systematic Review of the Literature. Respiration. 2016;91(3):215-27.

109. Casoni GL, Tomassetti S, Cavazza A, Colby TV, Dubini A, Ryu JH, et al. Transbronchial lung cryobiopsy in the diagnosis of fibrotic interstitial lung diseases. PLoS ONE [Electronic Resource]. 2014;9(2):e86716.

110. Colby TV, Tomassetti S, Cavazza A, Dubini A, Poletti V. Transbronchial Cryobiopsy in Diffuse Lung Disease: Update for the Pathologist. Arch Pathol Lab Med. 2016 Sep 02.

111. Tomassetti S, Wells AU, Costabel U, Cavazza A, Colby TV, Rossi G, et al. Bronchoscopic Lung Cryobiopsy Increases Diagnostic Confidence in the Multidisciplinary Diagnosis of Idiopathic Pulmonary Fibrosis. Am J Respir Crit Care Med. 2016 Apr 1;193(7):745-52.

112. American Thoracic Society/European Respiratory Society International Multidisciplinary Consensus Classification of the Idiopathic Interstitial Pneumonias. Am J Respir Crit Care Med. 2002;165(2):277-304.

113. Churg A, Muller NL, Flint J, Wright JL. Chronic hypersensitivity pneumonitis. Am J Surg Pathol. 2006 Feb;30(2):201-8.

114. Akashi T, Takemura T, Ando N, Eishi Y, Kitagawa M, Takizawa T, et al. Histopathologic analysis of sixteen autopsy cases of chronic hypersensitivity pneumonitis and comparison with idiopathic pulmonary fibrosis/usual interstitial pneumonia. Am J Clin Pathol. 2009 Mar;131(3):405-15. 
115. Takemura T, Akashi T, Kamiya H, Ikushima S, Ando T, Oritsu M, et al. Pathological differentiation of chronic hypersensitivity pneumonitis from idiopathic pulmonary fibrosis/usual interstitial pneumonia. Histopathology. 2012 Dec;61(6):1026-35.

116. Kambouchner M, Levy P, Nicholson AG, Schubel K, Magois E, Feuillet S, et al. Prognostic relevance of histological variants in nonspecific interstitial pneumonia. Histopathology. 2014 Oct;65(4):549-60.

117. Oda T, Ogura T, Kitamura H, Hagiwara E, Baba T, Enomoto $\mathrm{Y}$, et al. Distinct characteristics of pleuroparenchymal fibroelastosis with usual interstitial pneumonia compared with idiopathic pulmonary fibrosis. Chest. 2014 Nov;146(5):1248-55.

118. Atkins SR, Turesson C, Myers JL, Tazelaar HD, Ryu JH, Matteson EL, et al. Morphologic and quantitative assessment of $\mathrm{CD} 20+\mathrm{B}$ cell infiltrates in rheumatoid arthritis-associated nonspecific interstitial pneumonia and usual interstitial pneumonia. Arthritis Rheum. 2006 Feb;54(2):635-41.

119. Smith $M$, Dalurzo M, Panse P, Parish J, Leslie K. Usual interstitial pneumonia-pattern fibrosis in surgical lung biopsies. Clinical, radiological and histopathological clues to aetiology. J Clin Pathol. 2013 Oct;66(10):896-903.

120. Kawabata Y, Hoshi E, Murai K, Ikeya T, Takahashi N, Saitou Y, et al. Smoking-related changes in the background lung of specimens resected for lung cancer: a semiquantitative study with correlation to postoperative course. Histopathology. 2008 Dec;53(6):707-14.

121. Myers JL, Veal CJ, Shin MS, Katzenstein AL. Respiratory bronchiolitis causing interstitial lung disease. A clinicopathologic study of six cases. Am Rev Respir Dis. 1987;135(4):880-4.

122. Yousem SA, Colby TV, Gaensler EA. Respiratory bronchiolitis-associated interstitial lung disease and its relationship to desquamative interstitial pneumonia. Mayo Clin Proc. 1989;64(11):1373-80.

123. Yousem SA. Respiratory bronchiolitis-associated interstitial lung disease with fibrosis is a lesion distinct from fibrotic nonspecific interstitial pneumonia: a proposal. Mod Pathol. 2006 Nov;19(11):14749.

124. Churg A, Hall R, Bilawich A. Respiratory bronchiolitis with fibrosis-interstitial lung disease: a new form of smoking-induced interstitial lung disease. Arch Pathol Lab Med. 2015 Apr;139(4):437-40.

125. Flaherty KR, Fell C, Aubry MC, Brown K, Colby T, Costabel U, et al. Smoking-related idiopathic interstitial pneumonia. Eur Respir J. 2014 Sep;44(3):594-602.

126. Foy R, Hempel S, Rubenstein L, Suttorp M, Seelig M, Shanman R, et al. Meta-analysis: effect of interactive communication between collaborating primary care physicians and specialists. Ann Intern Med. 2010 Feb 16;152(4):247-58.

127. Flaherty KR, Andrei AC, King TE, Jr., Raghu G, Colby TV, Wells A, et al. Idiopathic interstitial pneumonia: do community and academic physicians agree on diagnosis? Am J Respir Crit Care Med. 2007 May 15;175(10):1054-60.

128. Flaherty KR, King TE, Jr., Raghu G, Lynch JP, 3rd, Colby TV, Travis WD, et al. Idiopathic interstitial pneumonia: what is the effect of a multidisciplinary approach to diagnosis? Am J Respir Crit Care Med. 2004 Oct 15;170(8):904-10.

129. Chaudhuri N, Spencer L, Greaves M, Bishop P, Chaturvedi A, Leonard C. A Review of the Multidisciplinary Diagnosis of Interstitial Lung Diseases: A Retrospective Analysis in a Single UK Specialist Centre. Journal of clinical medicine. $2016 \mathrm{Jul}$ 27;5(8).

130. Jo HE, Glaspole IN, Levin KC, McCormack SR, Mahar AM, Cooper WA, et al. Clinical impact of the interstitial lung disease multidisciplinary service. Respirology. 2016 Nov;21(8):1438-44. 
131. Ryerson CJ, Corte TJ, Lee JS, Richeldi L, Walsh SLF, Myers JL, et al. A Standardized Diagnostic Ontology for Fibrotic Interstitial Lung Disease: An International Working Group Perspective. Am J Respir Crit Care Med. 2017 Apr 17.

132. Salisbury ML, Xia M, Murray S, Bartholmai BJ, Kazerooni EA, Meldrum CA, et al. Predictors of idiopathic pulmonary fibrosis in absence of radiologic honeycombing: A cross sectional analysis in ILD patients undergoing lung tissue sampling. Respir Med. 2016 Sep;118:88-95.

133. Kim SY, Diggans J, Pankratz D, Huang J, Pagan M, Sindy N, et al. Classification of usual interstitial pneumonia in patients with interstitial lung disease: assessment of a machine learning approach using high-dimensional transcriptional data. Lancet Respir Med. 2015 Jun;3(6):473-82.

134. Pankratz DG, Choi Y, Imtiaz U, Fedorowicz GM, Anderson JD, Colby TV, et al. Usual Interstitial Pneumonia Can Be Detected in Transbronchial Biopsies Using Machine Learning. Ann Am Thorac Soc. 2017 Jun 22.

135. Washko GR, Lynch DA, Matsuoka S, Ross JC, Umeoka S, Diaz A, et al. Identification of early interstitial lung disease in smokers from the COPDGene Study. Academic radiology. 2010 Jan;17(1):4853.

136. Jin GY, Lynch D, Chawla A, Garg K, Tammemagi MC, Sahin H, et al. Interstitial Lung Abnormalities in a CT Lung Cancer Screening Population: Prevalence and Progression Rate. Radiology. 2013 Mar 19;268:563-71.

137. Putman RK, Hatabu H, Araki T, Gudmundsson G, Gao W, Nishino M, et al. Association Between Interstitial Lung Abnormalities and All-Cause Mortality. JAMA. 2016 Feb 16;315(7):672-81. 

Table 1: Key questions addressed by the working group

1. What specific clinical information is required to exclude other forms of interstitial lung disease?

2. What are the critical CT features that can be used to make the diagnosis of UIP/IPF?

3. How can UIP/IPF be distinguished on $\mathrm{CT}$ from other fibrosing interstitial pneumonias?

4. When is surgical or other biopsy indicated in the diagnosis of IPF?

5. What are the critical pathologic features that can be used to make the diagnosis of UIP/IPF?

6. How can UIP/IPF be distinguished histologically from other fibrosing interstitial pneumonias?

7. How should MDD be performed in the diagnosis of IPF?

a. Who should be engaged in MDD?

b. Which patients should undergo MDD?

c. What are the limitations of MDD? 


\section{Table 2. Clinical checklist for alternative diagnoses}

General

What are the severity, duration, and pace of the primary respiratory symptoms?

Systemic autoimmune disease (RA, SSC, PM/DM, SjS, MCTD) (see text)

Are there symptoms and/or signs of a systemic autoimmune disorder?

Are there serologic findings suggestive of an autoimmune disorder?

Other systemic disease (sarcoid, immune system abnormalities)

Is there evidence of other organ involvement?

Hypersensitivity pneumonitis (see text)

Does the patient have a clinically relevant exposure to an antigen, generally inhaled, known to result in the development of HP?

Do they have pets? What about birds?

To what are they exposed in their home or work environment? Is there water damage?

Is the exposure clinically significant?

Is the intensity clinically significant?

Is there a temporal relationship between the exposure and symptom onset?

Occupational/Environmental lung disease

Does the patient work in an occupation known to be at risk for the development of lung disease? What do they actually do in their current job? What about previous jobs?

\section{What avocational exposures exist?}

Drug-induced lung disease

Does the patient use any medicines, herbs, vitamins, supplements, or recreational drugs that could account for the presence of lung disease? 
Specific genetic syndromes (see text)

Is there a family history of lung fibrosis, or evidence of premature graying, cryptogenic cirrhosis, aplastic anemia, myelodysplasia, macrocytosis, or thrombocytopenia? 
Table 3: Diagnostic categories of UIP on CT

\begin{tabular}{|l|l|l|l|l|}
\hline & Typical UIP CT pattern & Probable UIP CT pattern & $\begin{array}{l}\text { CT pattern } \\
\text { Indeterminate for UIP }\end{array}$ & $\begin{array}{l}\text { CT features most consistent with } \\
\text { non-IPF diagnosis }\end{array}$ \\
\hline CT distribution & $\begin{array}{l}\text { Basal (occasionally diffuse) and } \\
\text { subpleural predominant. } \\
\text { Distribution is often } \\
\text { heterogeneous. }\end{array}$ & $\begin{array}{l}\text { Basal and subpleural } \\
\text { predominant. Distribution is } \\
\text { often heterogeneous. }\end{array}$ & Variable or diffuse & $\begin{array}{l}\text { Upper or mid lung predominant } \\
\text { fibrosis } \\
\text { Peribronchovascular predominance } \\
\text { with subpleural sparing }\end{array}$ \\
\hline CT features & $\begin{array}{l}\text { Honeycombing. } \\
\text { Reticular pattern with peripheral } \\
\text { traction } \\
\text { bronchiectasis/bronchiolectasis* } \\
\text { Absence of features to suggest } \\
\text { an alternative diagnosis }\end{array}$ & $\begin{array}{l}\text { Reticular pattern with peripheral } \\
\text { traction } \\
\text { bronchiectasis/bronchiolectasis* } \\
\text { Honeycombing is absent. }\end{array}$ & $\begin{array}{l}\text { Evidence of fibrosis } \\
\text { with some } \\
\text { inconspicuous features } \\
\text { suggestive of non-UIP } \\
\text { pattern* }\end{array}$ & $\begin{array}{l}\text { Any of the following: } \\
\text { Predominant consolidation } \\
\text { Extensive pure ground glass opacity } \\
\text { (without acute exacerbation) } \\
\text { Extensive mosaic attenuation with } \\
\text { extensive sharply defined lobular air } \\
\text { trapping on expiration } \\
\text { Diffuse nodules or cysts }\end{array}$ \\
\hline
\end{tabular}

* Reticular pattern is superimposed on ground glass opacity, and in these cases is usually fibrotic. Pure ground glass opacity however would be against the diagnosis of UIP/IPF and would suggest acute exacerbation, hypersensitivity pneumonitis or other conditions 
Table 4: Histopathologic criteria for UIP/IPF pattern

\begin{tabular}{|c|c|c|c|}
\hline UIP/IPF pattern & Probable UIP/IPF pattern & $\begin{array}{l}\text { Indeterminate for } \\
\text { UIP/IPF pattern }\end{array}$ & $\begin{array}{l}\text { Features most } \\
\text { consistent with an } \\
\text { alternative diagnosis }\end{array}$ \\
\hline $\begin{array}{l}\text { These cases show } \\
\text { features with all four } \\
\text { criteria present, and } \\
\text { lack features that } \\
\text { might suggest an } \\
\text { alternative } \\
\text { diagnosis } \\
\text { - Dense fibrosis } \\
\text { causing } \\
\text { architecture } \\
\text { remodeling with } \\
\text { frequent } \\
\text { honeycombing } \\
\text { - Patchy lung } \\
\text { involvement by } \\
\text { fibrosis } \\
\text { - Subpleural } \\
\text { and/or } \\
\text { paraseptal } \\
\text { distribution } \\
\text { Fibroblast foci at } \\
\text { the edge of } \\
\text { dense scars }\end{array}$ & $\begin{array}{l}\text { These cases show either } \\
\text { honeycomb fibrosis only, or } \\
\text { a severe fibrosing process } \\
\text { that falls short of showing } \\
\text { all four criteria for definite } \\
\text { UIP/IPF and lack features } \\
\text { that might suggest an } \\
\text { alternative diagnosis } \\
\text { - Dense fibrosis causing } \\
\text { architecture } \\
\text { remodeling with } \\
\text { frequent } \\
\text { honeycombing } \\
\text { - Patchy lung } \\
\text { involvement by fibrosis } \\
\text { - Fibroblastic foci at the } \\
\text { edge of dense scars } \\
\text { may or may not be } \\
\text { present } \\
\text { OR } \\
\text { Only honeycomb } \\
\text { fibrosis }\end{array}$ & $\begin{array}{l}\text { These cases show } \\
\text { evidence of a } \\
\text { fibrosing process but } \\
\text { show features more } \\
\text { in favor of either a } \\
\text { non-UIP pattern }{ }^{+} \text {, or } \\
\text { UIP in a setting other } \\
\text { than IPF }\end{array}$ & $\begin{array}{l}\text { (a) Non-UIP pattern } \\
\\
\text { (b) UIP pattern with } \\
\text { ancillary features } \\
\text { strongly suggesting } \\
\text { an alternative } \\
\text { diagnosis }^{*}\end{array}$ \\
\hline
\end{tabular}

${ }^{+}$Non-UIP pattern

- Cases with features of other fibrotic disorders, such as fibrotic hypersensitivity pneumonitis, fibrotic nonspecific interstitial pneumonitis, fibrosing organizing pneumonia, pleuroparenchymal fibroelastosis, pulmonary Langerhans Cell Histiocytosis, or smoking-related interstitial fibrosis (see text).

${ }^{\ddagger}$ UIP pattern with ancillary features suggesting an alternative diagnosis

- Examples include: Prominent diffuse alveolar damage or organizing pneumonia (Consider acute exacerbation of UIP); granulomas, (Consider hypersensitivity pneumonitis, sarcoid, infection); marked interstitial inflammatory cell infiltrate away from areas of UIP (Consider hypersensitivity 
pneumonitis, connective tissue disease); predominant airway centered changes (Consider hypersensitivity pneumonitis) 
Table 5: Desirable features of multidisciplinary conference

\begin{tabular}{|c|c|}
\hline Frequency & Weekly to monthly, depending on volume \\
\hline $\begin{array}{l}\text { Patient } \\
\text { selection }\end{array}$ & $\begin{array}{l}\text { Focus on patients with disease that is not fully characterized, and those with } \\
\text { suspicion of an underlying etiology (e.g. hypersensitivity pneumonitis, collagen } \\
\text { vascular disease). In experienced groups with high volume of patients, those with } \\
\text { typical features may not require review. Selected patients may also be re-reviewed } \\
\text { on followup. }\end{array}$ \\
\hline $\begin{array}{l}\text { Nature of } \\
\text { meeting }\end{array}$ & $\begin{array}{l}\text { Direct contact or telemedicine. Pathology and radiology should be directly } \\
\text { visualized }\end{array}$ \\
\hline Participants & $\begin{array}{l}\text { Clinician, radiologist, pathologist with interest/experience in ILD. If not } \\
\text { experienced, linkage to experienced group needed (e.g. electronic transmission of } \\
\text { images, review of slides, telephone or e mail discussion of clinical aspects) } \\
\text { Rheumatologist is often helpful. }\end{array}$ \\
\hline $\begin{array}{l}\text { Goals of } \\
\text { meeting }\end{array}$ & Diagnosis, management plan, review of disease progression \\
\hline Documentation & $\begin{array}{l}\text { First choice MD diagnosis (including "unclassifiable disease"), realistic differential } \\
\text { diagnoses, likely reversibility. Recommendations on additional diagnostic tests }\end{array}$ \\
\hline Communication & $\begin{array}{l}\text { Final multidisciplinary diagnosis recorded in case notes and communicated in } \\
\text { discharge statements. May also include list of participants, clinical, radiologic and } \\
\text { pathologic diagnoses, management recommendations. }\end{array}$ \\
\hline
\end{tabular}




\section{Table 6}

\section{Pathways to confident and working clinical-radiologic-pathologic diagnoses of IPF -}

1. When can one make a confident diagnosis of IPF without biopsy?

a. Clinical context of IPF*, with CT pattern of definite or probable UIP

2. When is a diagnostic biopsy necessary to make a confident diagnosis of IPF?

a. Clinical context of IPF with CT pattern either indeterminate or suggestive of an alternative diagnosis

b. Clinical context indeterminate for IPF** with any CT pattern.

3. When is MDD necessary in the context of suspected IPF?

a. Where the clinical context and/or the CT pattern are indeterminate

i. Outcome of MDD will be a decision whether to perform additional clinical evaluation and/or bronchoalveolar lavage and/or diagnostic biopsy.

b. After biopsy is performed, to integrate the clinical, imaging, and histologic features.

c. When diagnostic tissue is not available, to consider a working diagnosis of IPF

4. What should be done when diagnostic tissue is not available?

a. MDD with consideration of age, gender, smoking status, findings on bronchoalveolar lavage, and longitudinal disease behavior

b. In this context, a working diagnosis of IPF may be made in the presence of a progressive fibrosing interstitial pneumonia, in the absence of an alternative explanation. The level of diagnostic confidence of such a working diagnosis should be recorded, and the diagnosis should be reviewed at regular intervals, as it may change over time.

Definitions:

* Clinical context of IPF: All of the following: age > 60, absence of significant exposure, no evidence of collagen vascular disease.

** Clinical context indeterminate for IPF: Any of the following: age $\leq 60$, potentially significant exposure, or evidence of collagen vascular disease. 


\section{Figure 1}

Typical UIP CT pattern: Axial and coronal CT images (Figs 1a-e) show subpleural predominant reticular abnormality with traction bronchiectasis and honeycombing, with a clear craniocaudal gradient on coronal images. A magnified view of a different patient (Figure 1f) shows areas of honeycombing occurring in single and multiple layers (arrows). Additionally, two areas of apparent ground glass abnormality (circles) are shown on closer inspection to contain dilated bronchi (traction bronchiectasis), and therefore likely to represent fibrosis.

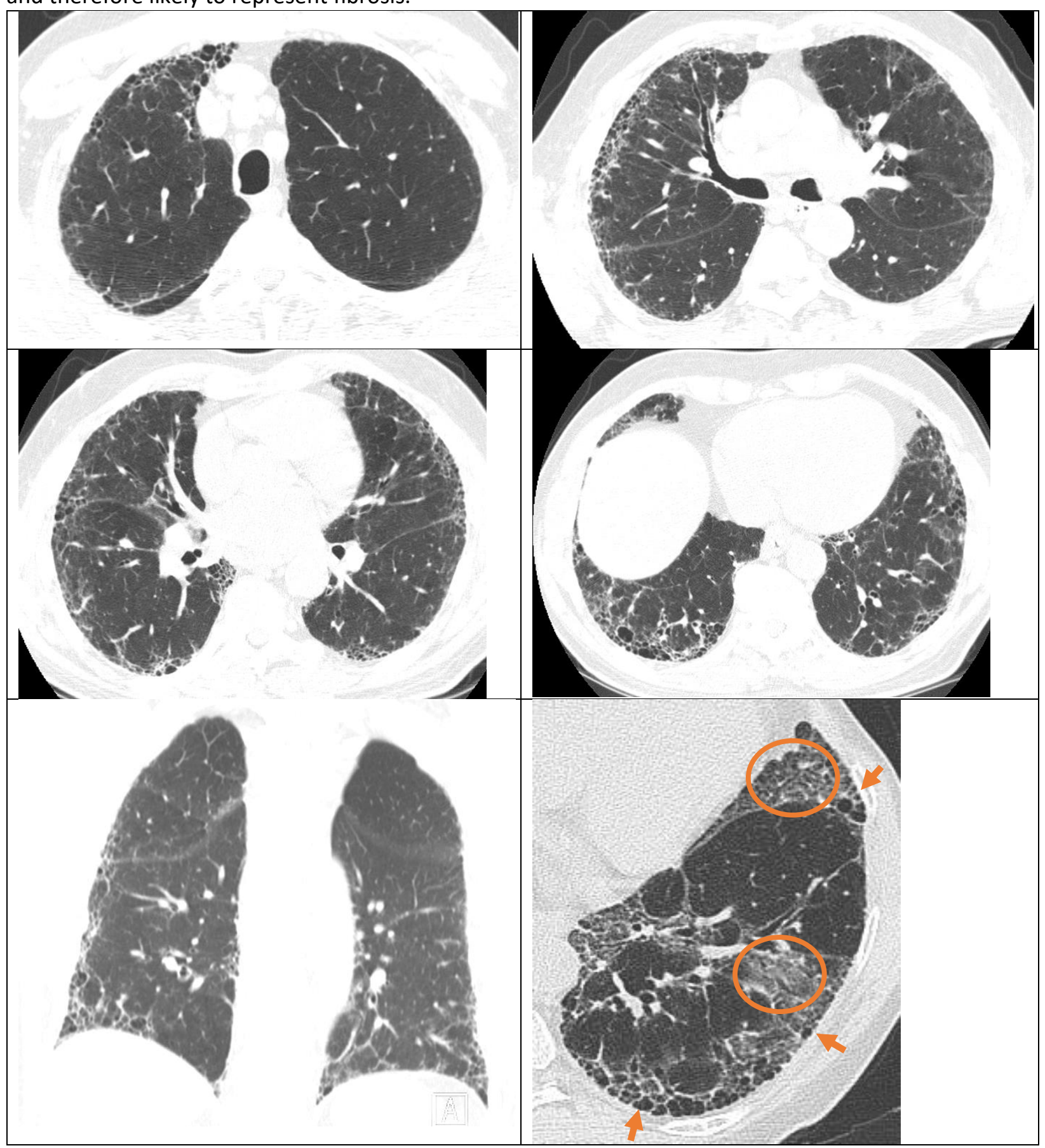


Figure 2

Probable UIP CT pattern: CT shows basal predominant subpleural predominant reticular abnormality with peripheral traction bronchiectasis (circles, Fig $2 \mathrm{~b}$ ) but no honeycombing. UIP was proven at histology.

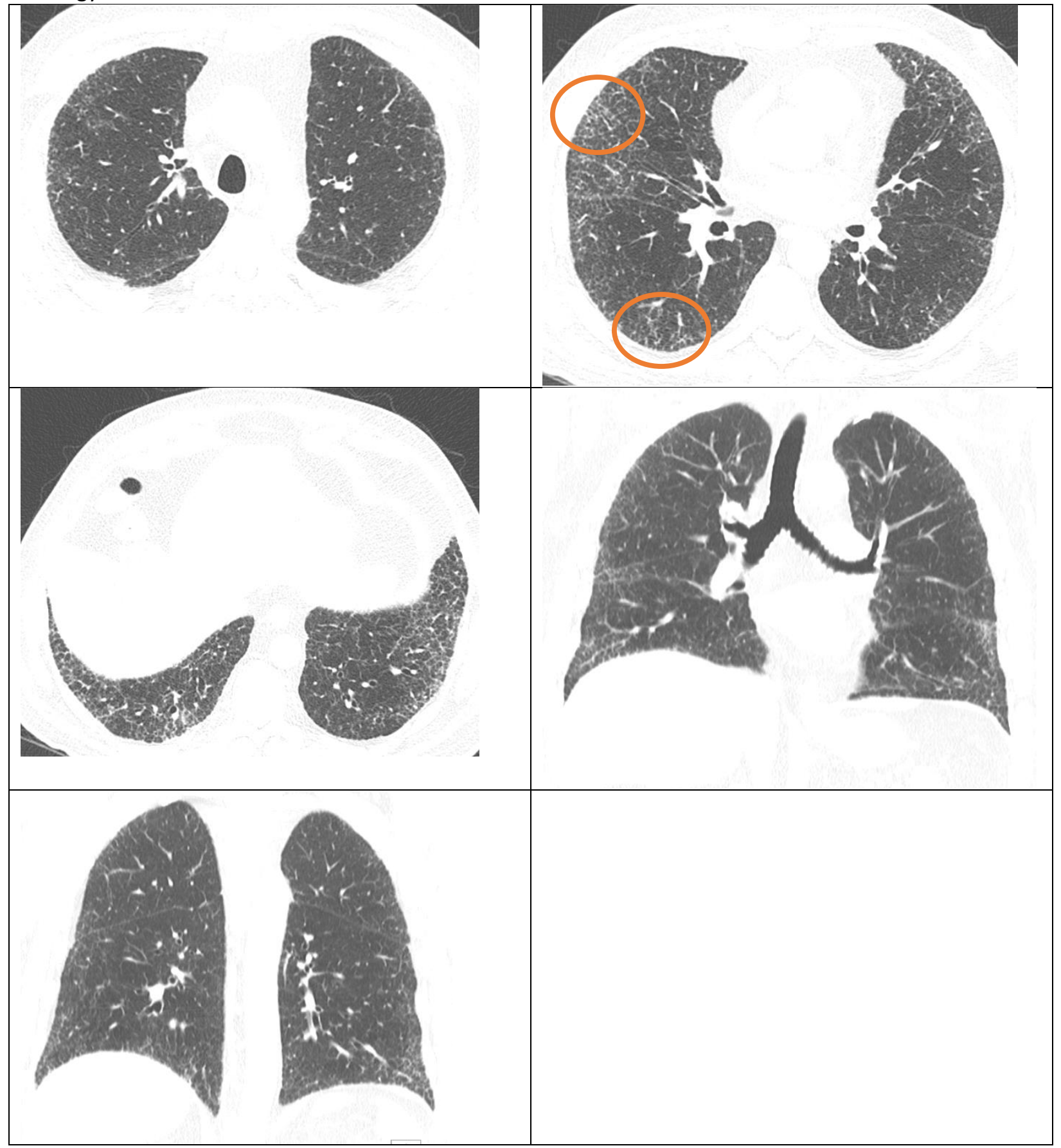


Figure 3

CT pattern indeterminate for UIP. CT shows reticular abnormality with traction bronchiectasis, without honeycombing. Although the abnormality is lower lung predominant, the findings are not typical for UIP because of peribronchovascular extension (Figure 3c), patchy ground glass abnormality and mosaic attenuation (Figure 3e). UIP was proven at biopsy.

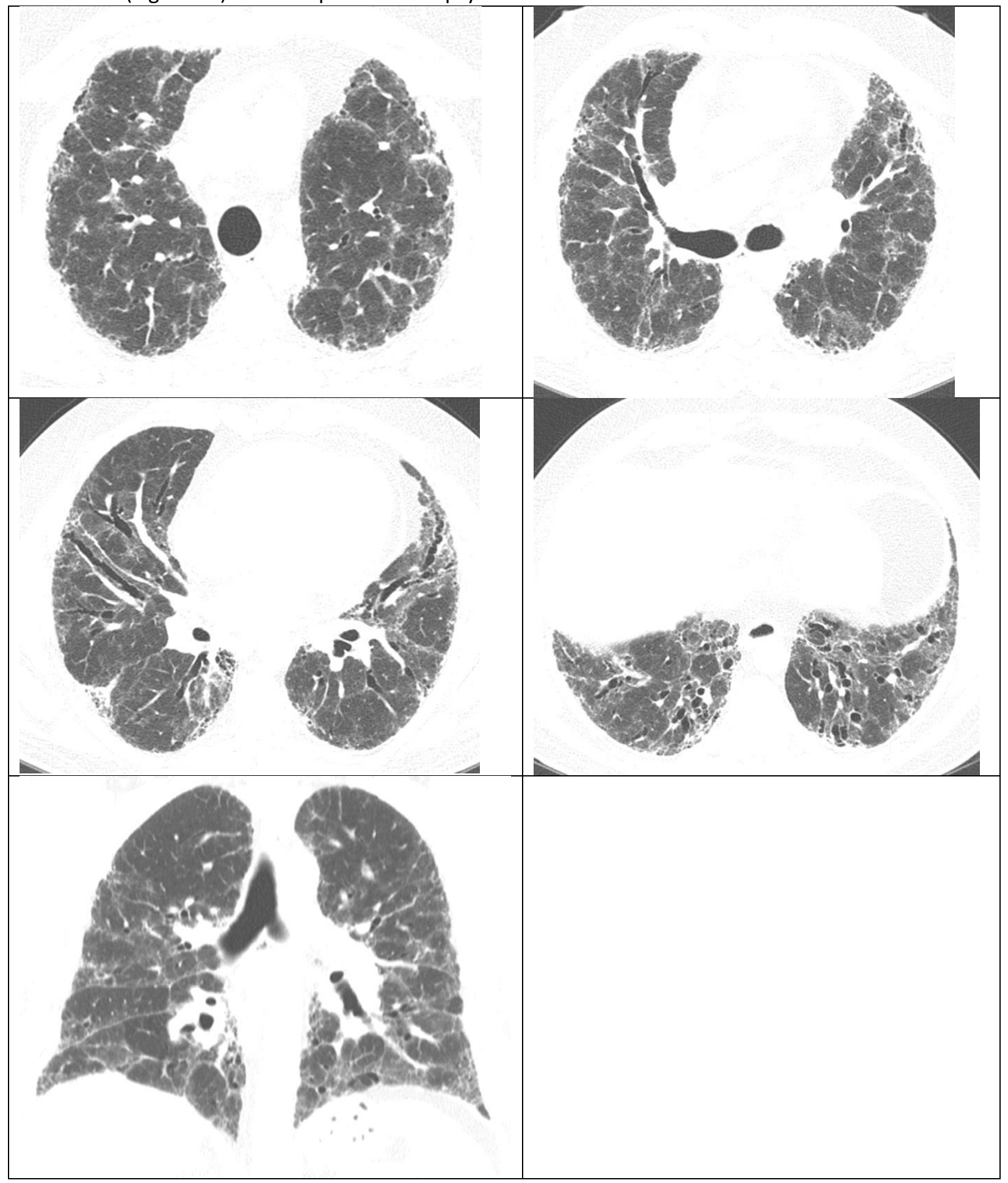


Figure 4

CT pattern indeterminate for UIP: inspiratory CT shows diffuse, peripheral predominant reticular opacities admixed with patchy areas of decreased (mosaic) attenuation (arrows). UIP was proven at biopsy.

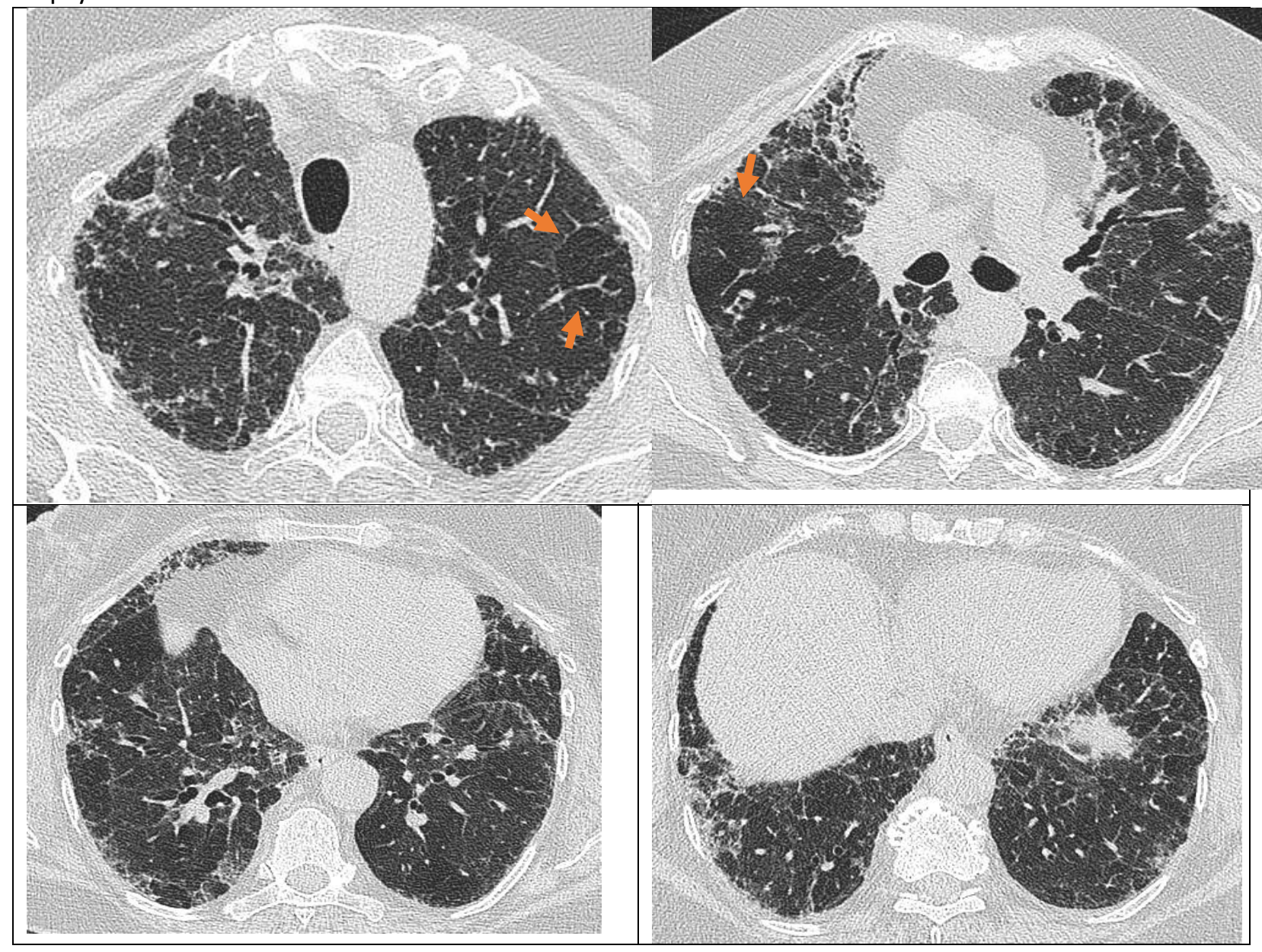




\section{Figure 5}

CT features most consistent with non-IPF diagnosis: inspiratory CT shows upper lobe predominant peribronchovascular (bronchocentric) reticular opacities, architectural distortion, and severe traction bronchiectasis, associated with areas of decreased attenuation (arrows). This CT pattern is consistent with fibrotic hypersensitivity pneumonitis.

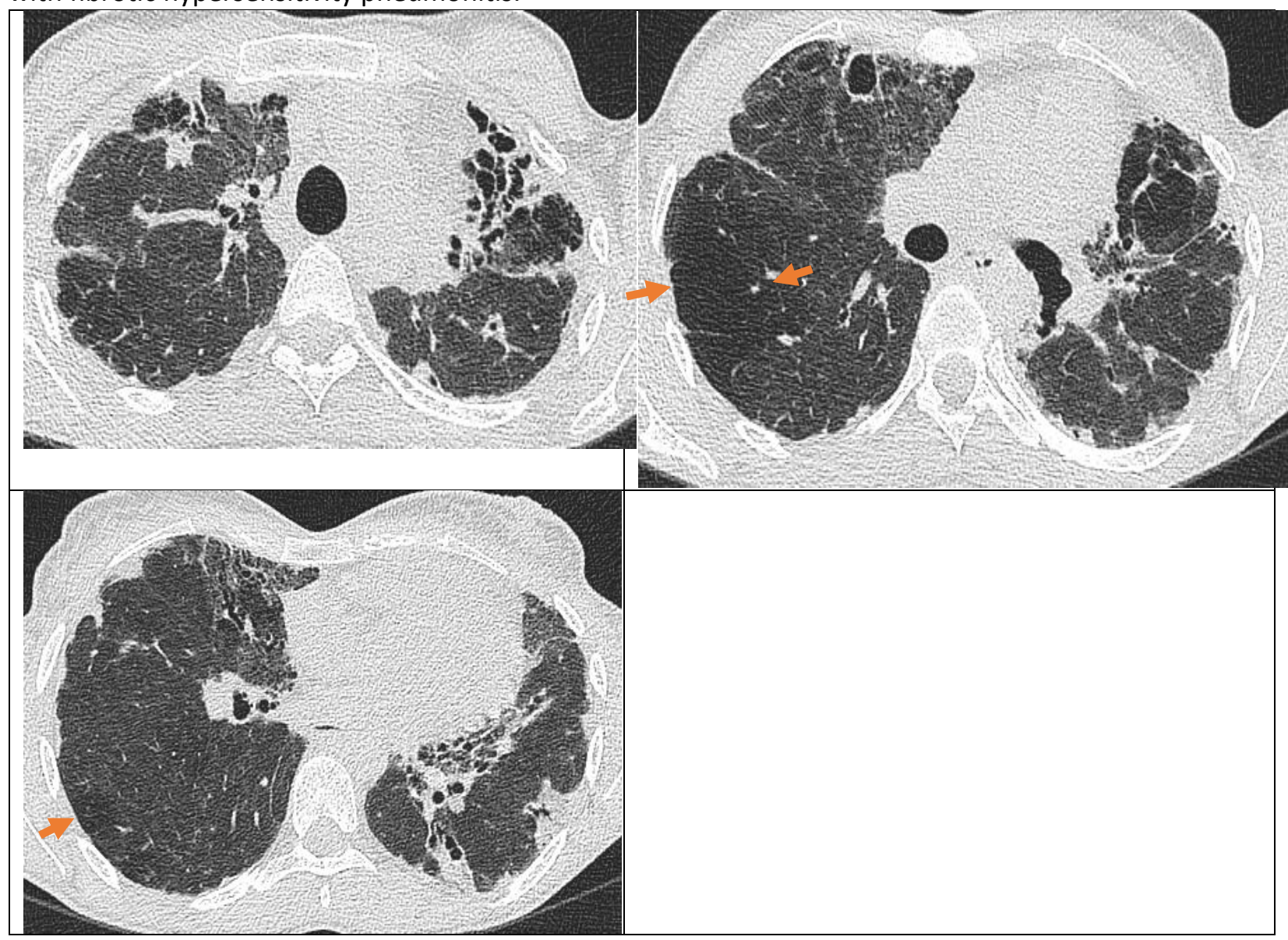


Figure 6

Fibroblastic focus

Fibroblast foci in UIP/IPF sometimes are highlighted by their basophilic appearance reflective of increased mucopolysaccharide associated with young fibrous tissue. The fibroblast foci (arrows) show prominent basophilia and again are rounded to convex in configuration and adjacent to dense scarring.

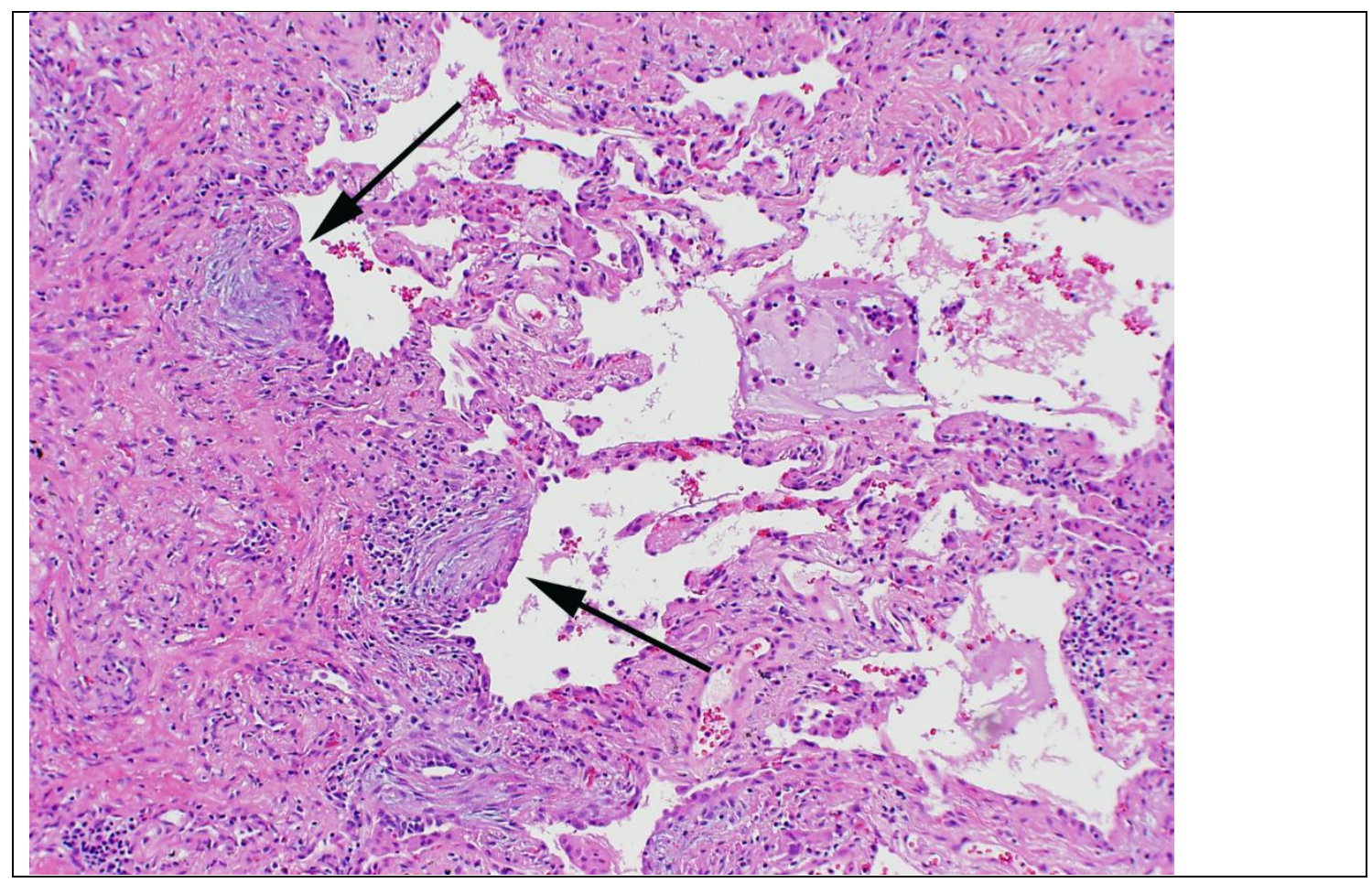


Figure 7

Definite UIP

Scanning power microscopy shows patchy subpleural and paraseptal scarring that includes some subpleural microscopic honeycombing (a, arrows). Higher power evaluation from the same case shows readily identifiable fibroblast foci ( $b$ and $c$, arrows). The fibroblast foci are pale and edematous and somewhat convex/rounded in appearance and adjacent to scarring. Such a case fulfills criteria for definite UIP/IPF.

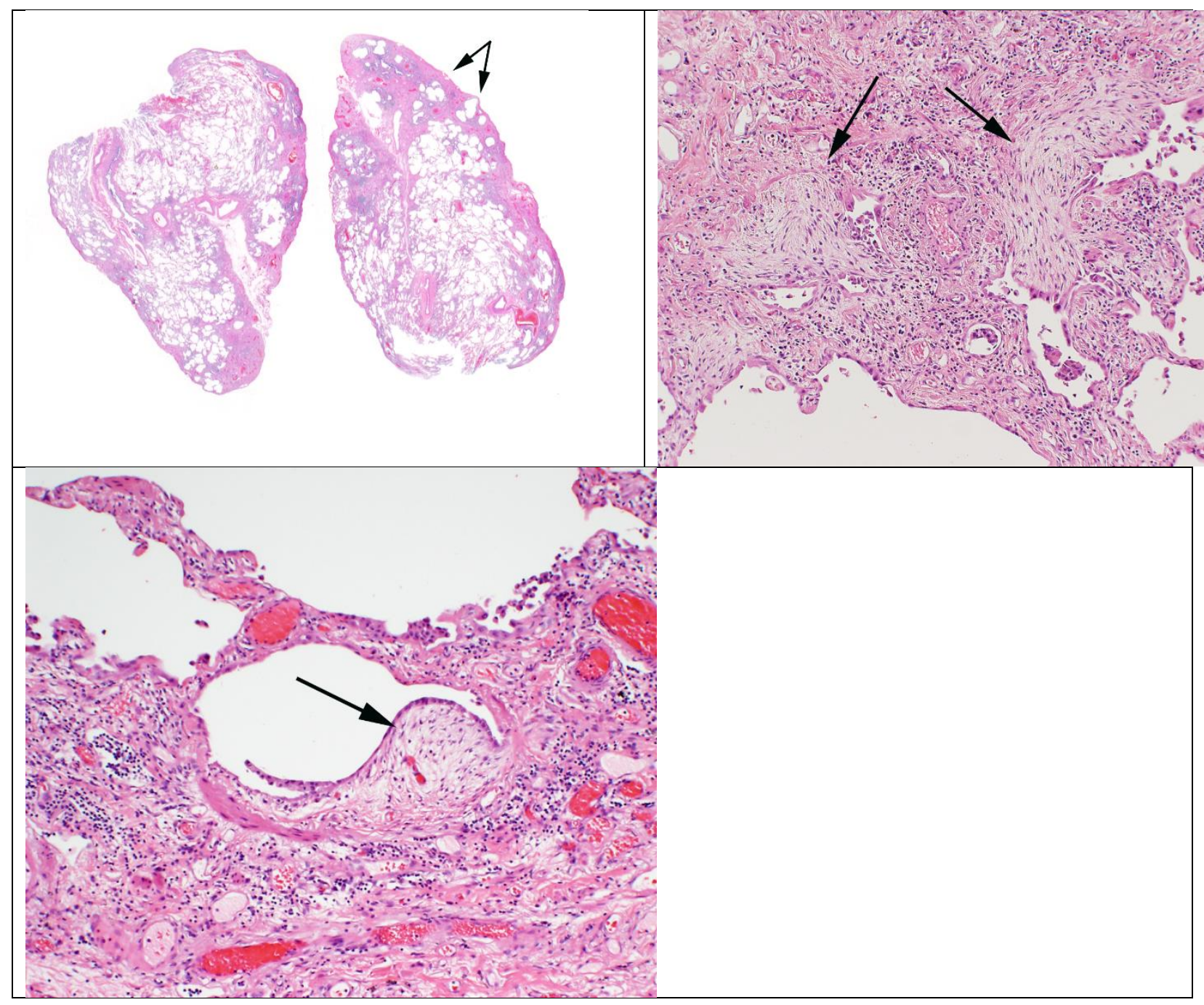


Figure 8

Probable UIP

Scanning power microscopy shows that the sampled tissue is entirely replaced by honeycomb change.

Such a biopsy, in the appropriate clinical setting, is designated probable UIP/IPF.

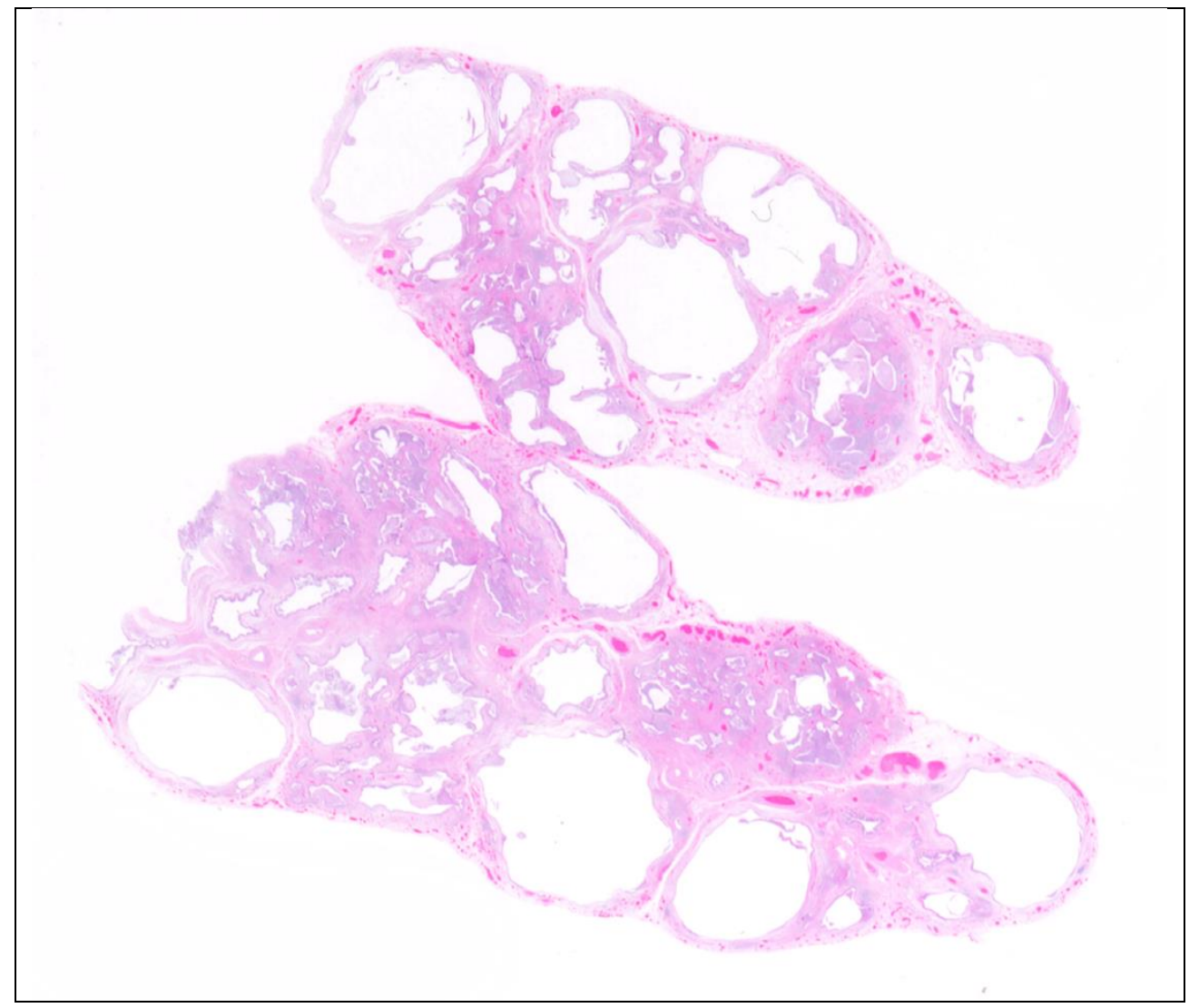




\section{Figure 9}

Suggestive of an alternative diagnosis: Chronic HP

Some regions show typical scanning power appearance of UIP with peripheral and subpleural scarring (a) and readily identifiable fibroblast foci (b, arrow). Other fields in the same case, however, show centrilobular injury $(c)$ with associated organizing pneumonia and small non-necrotizing granulomas $(d$, arrow) characteristic of HP.

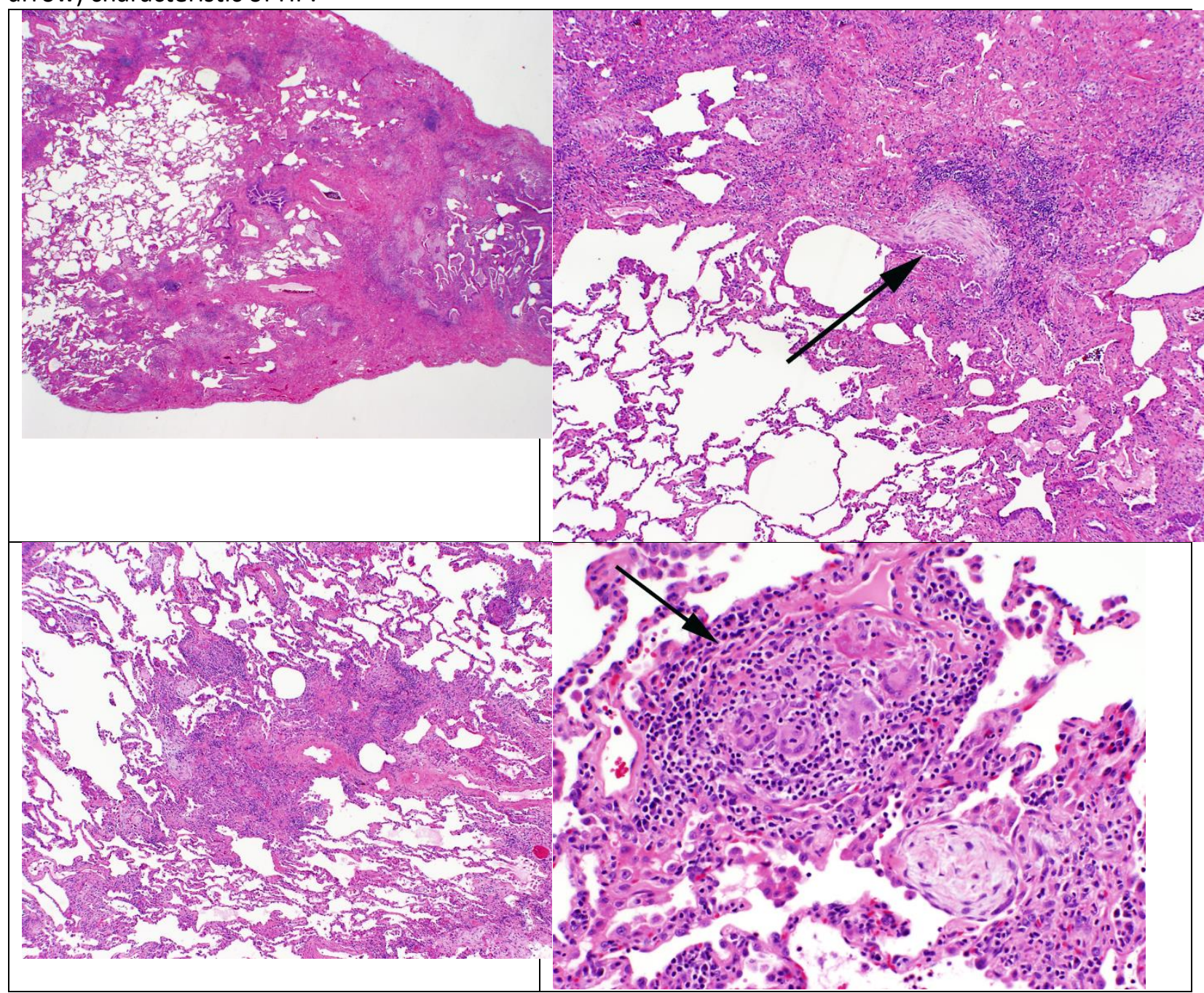




\section{Figure 10}

UIP in Connective tissue disease

This biopsy from a patient with rheumatoid arthritis and interstitial lung disease shows honeycomb change with prominent lymphoid hyperplasia with germinal centers, the latter being a clue to an underlying connective tissue disease. However, a few lymphoid follicles, including a rare germinal center, are not uncommon in UIP/IPF. Fibroblast foci were present in the regions of honeycombing in this case (b, center).

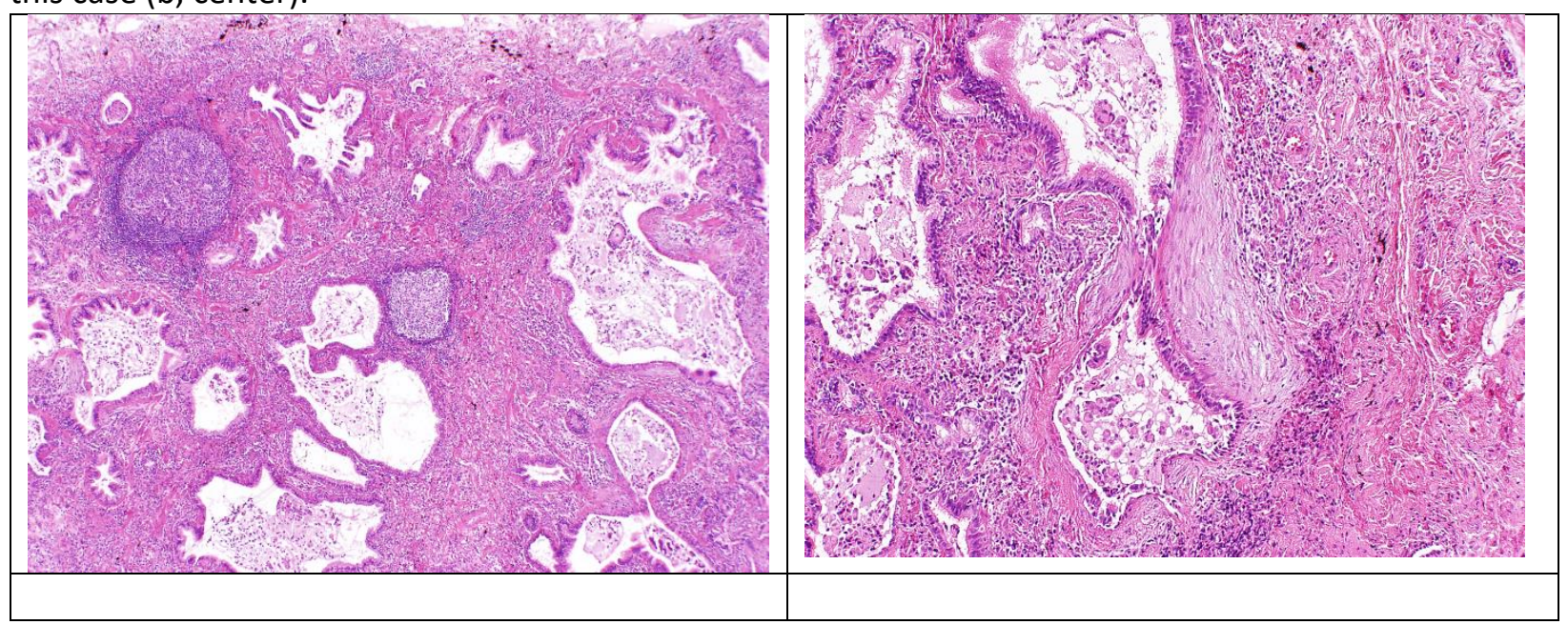

